\title{
Scheduling of a multiproduct pipeline system
}

\author{
R. Rejowski, Jr., J.M. Pinto* \\ Department of Chemical Engineering, University of São Paulo, Av. Prof. Luciano Gualberto, t.3, 380 Sao Paulo, SP 05508-900, Brazil
}

Received 6 February 2003; accepted 7 February 2003

\begin{abstract}
Pipelines provide an economic fluid transportation mode for petroleum systems, especially when large amounts of petroleum derivatives have to be pumped for long distances. The system reported in this paper is composed by an oil refinery, one multiproduct pipeline connected to several depots and to the local consumer markets that receive large amounts of oil products. Extensive distances must be covered to reach the depots and the pipeline operates intermittently due to periodic increases in energy costs. The pipeline is divided into segments that connect two consecutive depots and packs that contain one product that compose the segments. Mixed-integer linear programming optimization models that are generated from linear disjunctions and rely on discrete time are proposed for the scheduling system. In the first model it is assumed that the pipeline is divided into packs of equal size, whereas the second one relaxes such assumption. Key decisions of this model involve loading and unloading operations of tanks and of the pipeline These models satisfy all operational constraints, such as mass balances, distribution constraints, product demands, sequencing constraints and logical constraints for pipeline operation. Results generated include the inventory levels at all locations, the distribution of products among the depots and the best ordering of products in the pipeline. Two examples are solved, including a real-world system that is composed of five depots and distributes gasoline, diesel, liquefied petroleum gas and jet fuel for a 3-day time horizon.
\end{abstract}

(C) 2003 Elsevier Science Ltd. All rights reserved.

Keywords: Pipeline; Disjunctive programming; Logistics; Distribution scheduling; Optimization

\section{Introduction}

Planning activities related to product distribution have received growing interest in the past 20 years. Bodin, Golden, Assad, and Ball (1983) mention that annual transportation costs of consumer goods surpassed US $\$ 400$ billion in that decade. These high costs can be justified by the large volumes of raw materials and products.

Distribution and transfer operations of petroleum products can be carried out by road, railroad, vessel and pipeline. The latter has been usually utilized for crude oil transportation from terminals to refineries. Pipeline transportation is the most reliable and economical

* Corresponding author. Address: Department of Chemical Engineering, Chemistry and Materials Science, Polytechnic University, Six Metrotech Center, Brooklyn, NY 11201, USA. Tel.: +55-11-818-2237; fax: +55-11-813-2380.

E-mail addresses: jompinto@usp.br, rubens@lscp.pqi.ep.usp.br, j.pinto@poly.edu (J.M. Pinto). mode for large amounts of liquid and gaseous products. It differs from the remaining modes, since it may operate continuously (Sasikumar, Prakash, Patil, \& Ramani, 1997) and it is particularly important when large amounts of products have to be pumped for large distances.

Pipelines were first utilized by oil companies for crude oil transportation from terminals, where tankers unload and supply petroleum refineries. Pipelines have been used mainly by the Petroleum Industry for the last 40 years for transportation of petroleum and its derivatives.

For large consumer markets, where the demand for oil and its derivatives is high, oil companies are willing to expand pipeline utilization regarding its low operating cost. Pipelines must connect refineries to local distribution centers. Then, products are sent to consumer markets. As in the case of crude oil supply, pipelines must be operated efficiently such that the company may improve its operating margin (Jones \& Paddock, 1982). 


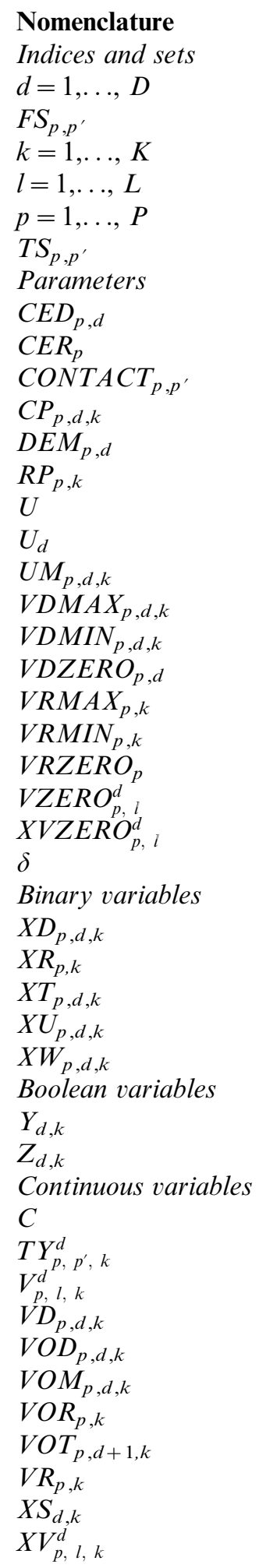

depots or segments

set of forbidden sequences between $p$ and $p^{\prime}$

time interval

packs

products

set of all possible sequences between $p$ and $p^{\prime}$

inventory unit cost of $p$ at depot $d$

inventory unit cost of $p$ at the refinery

transition cost from $p$ to $p^{\prime}$

unit cost for pumping $p$ to depot $d$ at $k$

demand of $p$ at consumer market supplied at depot $d$

production rate of $p$ at the refinery

volume of packs

volume of packs of segment $d$

upper bound on the volume of $p$ sent by $d$ at $k$

maximum volumetric capacity of $p$ at depot $d$ at time $k$

minimum volumetric capacity of $p$ at depot $d$ at time $k$

initial inventory level of $p$ at depot $d$

maximum volumetric capacity of $p$ at the refinery at time $k$

minimum volumetric capacity of $p$ at the refinery at time $k$

initial inventory level of $p$ at the refinery

initial inventory level of $p$ at pack $l$ of segment $d$

logical parameter ( 1 or 0 ) denoting initial inventory of $p$ at pack $l$ of segment $d$

duration of time intervals

1 if the depot $d$ receives product $p$ from the pipeline at time $k$

1 if the refinery discharges $p$ in the pipeline at time $k$

1 if $p$ is sent to segment $d$ at time $k$

denotes if pack $L$ from segment $d$ is completely sent to depot $d$

denotes if pack $L$ from segment $d$ is sent to depot $d$ and to segment $d+1$

true if pipeline segment $d$ is under transfer at time $k$

true if pipeline segments $d$ and $d+1$ are under transfer at time $k$

total cost to be minimized

transition variable (0-1) between $p^{\prime}$ and $p$ at time $k$ in segment $d$

volume of pack $l$ that contains $p$ at time $k$ in segment $d$

volumetric inventory level of $p$ at depot $d$ at $k$

volume of $p$ received by depot $d$ at $k$

volume of $p$ sent by depot $d$ to the local consumer market at time $k$

volume of $p$ sent by the refinery to the pipeline at $k$

volume of $p$ sent from segment $d$ to segment $d+1$ at time $k$

volumetric inventory level of $p$ at the refinery at $k$

denotes if segment $d$ is under operation at time $k$

denotes if pack $l$ contains product $p$ at time $k$ in segment $d$
Because of the magnitude and complexity of an oil system, a complete logistic project with reasonable level of detail becomes infeasible. Many authors propose a unified model for production and distribution of goods such as Vakharia, Erengüç, and Simpson (1999) and
Das and Sarin (1994) in the context of single batch plants and Wilkinson, Shah, and Pantelides (1994) and Wilkinson, Cortier, Shah, and Pantelides (1996) for multisite plants. In the Chemical Industry, Maturana and Contesse (1998) described the development of an 
mixed-integer linear programming (MILP) for optimizing the complete logistic system of sulfuric acid. Largescale fertilizer plants were involved in the system and one of the main complexities relates to the storage of such product. Several transportation modes were involved such as rail, truck and pipeline. Tahmassebi (1998) presents a complex distribution network for raw materials and products. Escudero, Quintana, and Salmerón (1999) propose an aggregate LP model that handles the supply, transformation and distribution of an oil company that accounts for uncertainties in supply costs, demands and product prices.

The use of optimization techniques for refinery scheduling has received growing interest, despite the fact that most of these still rely on production worksheets (Bonnelle \& Bos Feldman, 1999). Shobrys and White (2000) and Katzer, Ramage, and Sapre (2000) mention the importance of MINLP models for the programming of operations in oil refineries because of the inherent nonlinearities of chemical processes and of the possibility of representing discontinuous functions. Pinto, Joly, and Moro (2000) present optimization models for planning and scheduling in petroleum refineries. A planning model that relies on nonlinear blending relationships and on a general refinery topology is applied to several real-world scenarios. Mixed integer models handle several subsections of the refinery, such as the Liquefied Petroleum Gas (LPG) production unit. Lee, Pinto, Grossmann, and Park (1996) develop a MILP model for the management and scheduling of crude oil that considers blending specification for the types of crude oil. Shah (1996) presents an MILP for crude oil scheduling of a system consisting of one port that connects one refinery through a pipeline. Moro and Pinto (1998) studied the efficiency of an MILP for the allocation of crude oil into tanks, whereas Pinto and Joly (2000) propose mixedinteger-programming models for the scheduling of asphalt and lube oil that relies on nonlinear equations for blending operations. MILP and MINLP models were compared in terms of resulting schedules and computational performance.

Sasikumar et al. (1997) present a scheduling problem that concerns one pipeline that receives products from a refinery and supplies several depots connected to it. The pipeline is the only system that can transport several petroleum derivatives and therefore the refinery must store efficiently the several products and minimize product contamination. Techo and Holbrook (1974) and Zhao-ying (1986) also illustrate simplified models for transportation of crude oil and petroleum products in complexes with multiple pipelines.

Más and Pinto (2003) developed MILP models for the oil supply problem in a complex that involves tankers, piers, storage tanks and refineries. The terminals comprise piers, which receive vessels for discharging, storage tanks and a network that connects each other. The refineries have their own storage infrastructure and are considered constant level consumers. The problem involves a number of other issues, including intermediate storage, settling tasks and allocation of crude oil by its qualitative characteristics.

Several approaches other than mathematical programming were applied to similar problems. Ponce de Leão and Matos (1999) studied the design of electrical distribution networks, and applied simulated annealing, due to the large problem size. Pirkul and Jayaraman (1998) discuss the development of a two-stage commodity distribution network. The solution method relies on Lagrangean relaxation, which was the same approach utilized by Van der Bruggen, Gruson, and Salomon (1995) for the reformulation of the distribution network of a large oil company. Zhao-ying (1986) presents a dynamic programming approach to an oil distribution network through pipelines, whereas Sasikumar et al. (1997) apply the Beam Search method to the solution of the scheduling problem of oil derivatives through a pipeline.

The system considered in this work is composed by one petroleum refinery, one multi product pipeline and several depots that are connected to local consumer markets. Large amounts of oil derivatives that are generated in the refinery must be pumped through long distances until they achieve their destinations. The distribution element arises both from the transfer of products from the refinery and from the transfer to local markets. The major obstacles faced in these operations concern the satisfaction of product demands by the several consumer markets and their large variation within a small time horizon. Moreover, product sequencing is subject to constraints, which further complicates the generation of optimal schedules for the system operation.

MILP models are proposed for the simultaneous optimization of systems with multiple depots. These models must satisfy all the operational constraints, such as mass balances, distribution constraints, product demands and storage requirements. Such models rely on a uniform discrete time representation and on a logical formulation generated from linear disjunctions.

The results generated by these models are the inventory level profiles for all products at the refinery, at all pipeline segments and at the depots along the distribution horizon. The model formulations were tested and compared for systems containing up to five depots. This approach was successfully tested in a realworld system that transports four products, named OSBRA that must feed five distribution depots in the southeast and central regions from the REPLAN refinery in Paulínia (SP, Brazil). 


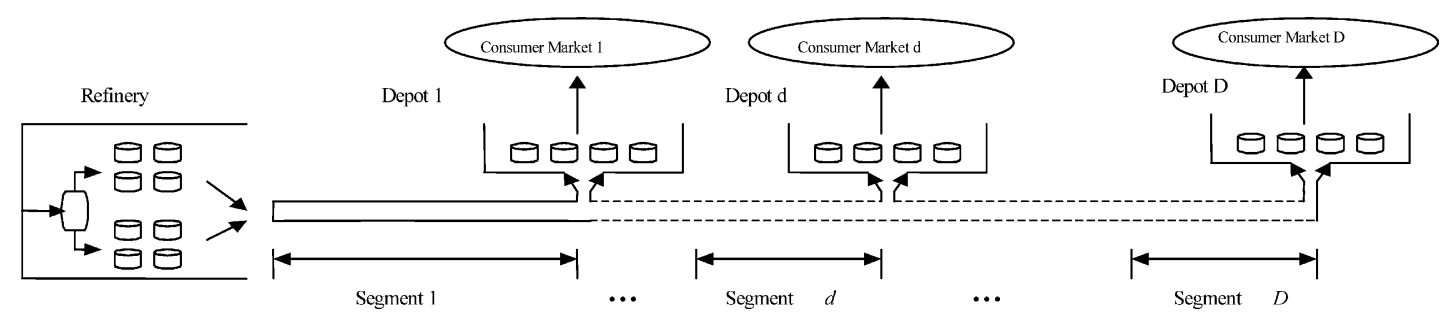

Fig. 1. Distribution pipeline system.

\section{Problem definition}

A refinery must distribute $P$ petroleum products among $D$ depots connected to a single pipeline, which is divided into $D$ segments. The depots have to satisfy requirements determined by local consumer markets. The pipeline system is represented in Fig. 1. Note that a segment is defined as a part of the pipeline comprised between two consecutive storage centers (refinery and depots).

The products that are generated at the refinery must be stored in dedicated tanks. According to Sasikumar et al. (1997), decisions that are typically involved in the refinery are the choice of product to be sent to the pipeline, its amount and distribution among the several depots. In the present case, the production profile for all products is known a priori since the tanks that feed the pipeline receive products from the refinery in intermittent mode.

It is important to note that in the refinery as well as in the distribution depots there may be more than one tank for each product. However, at most one tank must be connected to the pipeline at each time.

In the pipeline, each segment either transfers products to the depots or to the next segment. Moreover, product transfer must satisfy constant volume and maximum flow rate constraints in the pipeline. There are also forbidden sequences of products in the pipeline. The operation of multi-product pipelines presents a unique feature that is product contamination. Although pipelines provide a safe and reliable mode of transportation, product contamination is inevitable (Sasikumar et al., 1997). It occurs in the interface of two miscible products. Jones and Paddock (1982) mention that this interface must be received in a segregated tank for reprocessing in the refinery. There is another possibility that is to add this interface to a large amount of one of the products, such that its specification is not violated. One last possibility is to install separation units at several distribution depots.

The main consequence of such contamination is the increase in operating costs. Related costs are so high that Techo and Holbrook (1974) mention that the pipeline complex studied by the authors has an object of the minimization of interface costs that are related to the product flow rate.
The depots have to control their inventory levels and at the same time fulfill product demands established by the local consumer markets. The main challenges faced by the schedulers of distribution systems are the high demand levels for products in all depots and the electrical cost fluctuation. Demands must be satisfied according to inventory levels in the refinery and to the pipeline capacity. It is important to note that since there is only one pipeline and very large distances must be covered, it is critical that the correct decisions are made, since delays of up to fifteen days may occur.

The correct management of the distribution depots requires basically one major decision at each time period, that is the transfer of products to the consumer markets. Constraints are imposed by the lower and upper bounds on tank capacities, by the transportation time and by the timing of the unloading operations from the pipeline. Lack of products in the tanks affect local consumers, whereas excess may paralyze the transfer in the pipeline and even interrupt production in the refinery (Sasikumar et al., 1997).

Operating costs include inventory costs in the refinery as well as in the depots, pumping costs and finally transition costs between different products inside the pipeline.

Inventory costs are proportional to the stored amounts of products in all subsystems as well as to the time these remain in the tanks for all systems. Moreover, each locality is represented by an inventory cost coefficient. Pumping costs are proportional to the amount of product sent by the refinery and to the distance it must cover along the pipeline. Pumping cost coefficients depend on the distances of the depots from the refinery. Moreover, it becomes very important to define a distribution schedule that considers time periods of intensive energy consumption. These correspond to time periods comprised between 5 and 8 p.m. every weekday. Consequently, in these periods there is a significant increase in pumping costs and therefore an optimal operation should not transfer products within the peak period or use the pipeline as little as possible if demand levels are such that cannot be fulfilled in normal hours. The most challenging cost term is the one that accounts for transition costs. There is one cost for each pair of products that represents losses as well as interface reprocessing in each of the distribution depots. 


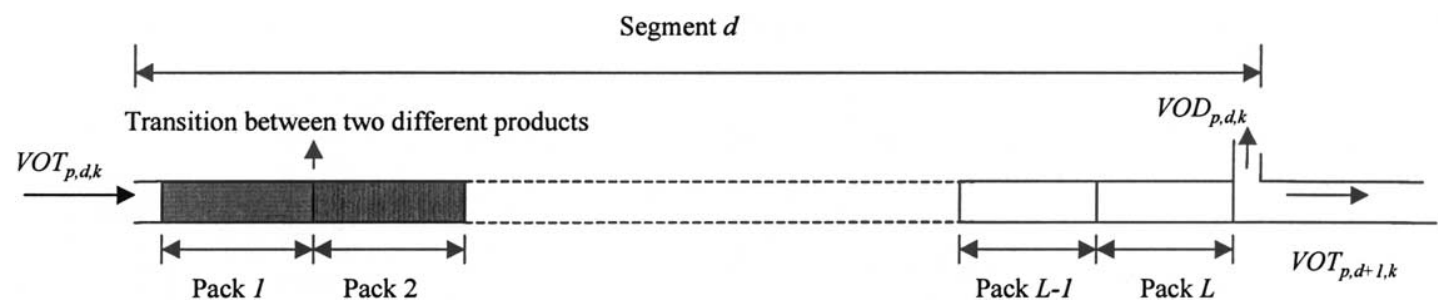

Fig. 2. Generic pipeline segment.

Due to the large number of decisions concerning the system, only a systematic approach may guide the establishment of an optimal operating policy.

\section{Optimization model}

\subsection{Description of the proposed models}

The present mathematical model must represent the correct operational mode of the refinery, the pipeline segments and finally the local depots. The most challenging factor is that product transfer can be temporarily interrupted along the time horizon. Due to this feature, the representation used for this system is based on that of Fig. 2.

Consider a generic segment $d$ of the pipeline that contains $L$ packs. All packs of the same segment have equal capacity. Each one contains exactly one product at every time interval. If a volume $V_{p}, d, k$ of product $p$ enters segment $d$ at time $k$, the content of the first pack in that segment is displaced to the next pack. The same occurs to all packs in the same segment. Consequently, the same amount of product must either leave the segment $\left(V O D_{p, d, k}\right)$ or be transferred to segment $d+$ $1\left(V O T_{p, d+1, k}\right)$. If no product enters $d$ at time $k$ $\left(V O T_{p, d, k}=0\right)$ then all packs keep their content.

The main assumptions are as follows:

1) All products have constant densities;

2) The production rate and demands are known during the time horizon;

3) All tanks are treated as aggregated capacities;

4) At most one tank at the refinery and at all depots can be connected to the pipeline at any time;

5) The pipeline segments are always completely filled.

Two models that rely on the previous assumptions are presented in this section. First, a model that considers packs of equal volumetric capacity is developed. Then, this assumption is relaxed in the second model. The nomenclature applied in both models for the generic system composed by $P$ products, $D$ depots and pipeline segments (see Figs. 1 and 2) is given at the end of the paper.

\subsection{Model MI - packs with equal volumetric capacity}

The tanks at the refinery are modeled by constraints (Eqs. (1a), (1b), (2) and (3)). Eq. (1a) and Eq. (1b) represent the volumetric balances for all products at any time interval, while the minimum and maximum capacities are imposed in constraint (Eq. (2)). The volumes that leave the tanks and feed the pipeline are related to binary variables $X R_{p, k}$ in Eq. (3).

$$
\begin{aligned}
& V R_{p, k}=V R Z E R O_{p}+R P_{p, k} \times \delta-V O R_{p, k} \\
& \quad \forall p, k=1 \\
& V R_{p, k}=V R_{p, k-1}+R P_{p, k} \times \delta-V O R_{p, k} \\
& \quad \forall p, k=2, \ldots, K \\
& V R M I N_{p, k} \leqslant V R_{p, k} \leqslant V R M A X_{p, k} \quad \forall p, k \\
& V O R_{p, k}=X R_{p, k} \times U \quad \forall p, k
\end{aligned}
$$

The constraints for the first pipeline segment are represented by disjunctions that are shown in Eqs. (4a) and (4b) (Raman \& Grossmann, 1994). Boolean variable $Y_{1, k}$ is true if the segment is under transfer and false otherwise.

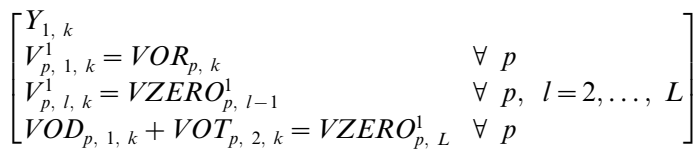

$$
\begin{aligned}
& \vee\left[\begin{array}{ll}
\neg Y_{1, k} & \\
V_{p, 1, k}^{1}=V Z E R O_{p, 1}^{1} & \forall p \\
V_{p, l, k}^{1}=V Z E R O_{p, l}^{1} & \forall p, l=2, \ldots, L \\
V O D_{p, 1, k}+V O T_{p, 2, k=0} & \forall p
\end{array}\right] \\
& k=1 \\
& {\left[\begin{array}{ll}
Y_{1, k} & \\
V_{p, 1, k}^{1}=V O R_{p, k} & \forall p \\
V_{p, l, k}^{1}=V_{p, l-1, k-1}^{1} & \forall p, l=2, \ldots, L \\
V O D_{p, 1, k}+V O T_{p, 2, k}=V_{p, L, k-1}^{1} & \forall p
\end{array}\right]} \\
& \vee\left[\begin{array}{ll}
\neg Y_{1, k} & \forall p \\
V_{p, 1, k}^{1}=V_{p, 1, k-1}^{1} & \forall p, l=2, \ldots, L \\
V_{p, l, k}^{1}=V_{p, l, k-1}^{1} & \forall p \\
V O D_{p, 1, k}+V O T_{p, 2, k}=0 & \forall p
\end{array}\right] \\
& k=2, \ldots, K
\end{aligned}
$$

Note that $Y_{1, k}$ is associated to decision variable $X S_{1, k}$ or in general terms $Y_{d, k}$ relates to decision variable $X S_{d, k}$ for segment $d$. The basic idea of the approach is to assign logical variables $X V_{p, l, k}^{d}$ to each set (product, depot, pack, time) to control pipeline operation. These are related to variables $V_{p, l, k}^{d}$ that denote volumes, as shown in Eq. (11). For instance, if there is transfer of 
product $p$ at time $k\left(X R_{p, k}=1\right.$ and from Eq. (5) $\left.X S_{1, k}=1\right)$ constraint (Eq. (8)) activates $X V_{p, 1, k}^{1}$. Note that the other transfers between packs $(l=2, \ldots, L)$ are activated in a chain effect through Eqs. (9a) and (9b). Otherwise $\left(X R_{p, k}=X S_{1, k}=0\right)$, the product contained in pack $l$ at time $k$ remains in it, as imposed by Eqs. (10a) and (10b). The same logic follows for all the remaining segments.

$$
\begin{aligned}
& \sum_{p=1}^{p} X R_{p, k}=X S_{d, k} \quad \forall k, d=1 \\
& X S_{d, k} \leqslant 1 \quad \forall d, k \\
& \sum_{p=1}^{p} X V_{p, l, k}^{d}=1 \quad \forall d, l, k \\
& X V_{p, l, k}^{d} \geqslant X R_{p, k} \quad \forall p, k, \quad d=1, \quad l=1 \\
& X V_{p, l, k}^{d} \geqslant X V Z E R O_{p, l-1}^{d}-\left[1-X S_{d, k}\right] \quad \forall p, d, \\
& l=2, \ldots, L, \quad k=1 \\
& X V_{p, l, k}^{d} \geqslant X V_{p, l-1, k-1}^{d}-\left[1-X S_{d, k}\right] \quad \forall p, d, \\
& l=2, \ldots, L, \quad k=2, \ldots, K \\
& X V_{p, l, k}^{d} \geqslant X \operatorname{VZERO} O_{p, l}^{d}-X S_{d, k} \quad \forall p, d, l, \\
& k=1 \\
& X V_{p, l, k}^{d} \geqslant X V_{p, l, k-1}^{d}-X S_{d, k} \quad \forall p, d, l, \\
& k=2, \ldots, K \\
& V_{p, l, k}^{d}=X V_{p, l, k}^{d} \times U_{d} \quad \forall p, d, l, k \\
& \sum_{p=1}^{p}\left[X D_{p, d, k}+X T_{p, d+1, k}\right]=X S_{d, k} \\
& \forall k, \quad d<D \\
& X D_{p, d, k}+X T_{p, d+1, k} \geqslant X V Z E R O_{p, l}^{d}-\left[1-X S_{d, k}\right] \\
& \forall p, \quad d<D, \quad l=L, \quad k=1 \\
& X D_{p, d, k}+X T_{p, d+1, k} \geqslant X V_{p, d, l, k-1}-\left[1-X S_{d, k}\right] \\
& \forall p, \quad d<D, l=L, \quad k=2, \ldots, K \\
& V O D_{p, d, k}=X D_{p, d, k} \times U \quad \forall p, d, k \\
& V O T_{p, d, k}=X T_{p, d, k} \times U \quad \forall p, d, k \\
& V O T_{p, d, k}=0 \quad \forall p, d=1, k
\end{aligned}
$$

For an intermediate segment $d$, the disjunctions presented in Eqs. (4a) and (4b) can be generalized as shown in Eq. (16a) for the first time interval and Eq. (16b) for the remaining ones.

$$
\begin{aligned}
& {\left[\begin{array}{ll}
Y_{d, k} & \forall p \\
V_{p, 1, k}^{d}=V O T_{p, d, k} & \forall p, l=2, \ldots, L \\
V_{p, l, k}^{d}=V Z E R O_{p, l-1}^{d} & \\
V O D_{p, d, k}+V O T_{p, d+1, k}=V Z E R O_{p, L}^{d} & \forall p
\end{array}\right]} \\
& \quad \vee\left[\begin{array}{ll}
\neg Y_{d, k} \\
V_{p, 1, k}^{d}=V Z E R O_{p, 1}^{d} \\
V_{p, l, k}^{d}=V Z E R O_{d, l}^{d} & \forall p \\
V O D_{p, d, k}+V O T_{p, d+1, k=0}=0 & \forall p
\end{array}\right] \\
& k=1
\end{aligned}
$$

$$
\begin{aligned}
& {\left[\begin{array}{ll}
Y_{d, k} & \\
V_{p, 1, k}^{d}=V O R_{p, k} & \forall p \\
V_{p, l, k}^{d}=V_{p, l-1, k-1}^{d} & \forall p, l=2, \ldots, L \\
V O D_{p, d, k}+V O T_{p, d+1, k}=V_{p, L, k-1}^{d} & \forall p
\end{array}\right]}
\end{aligned}
$$

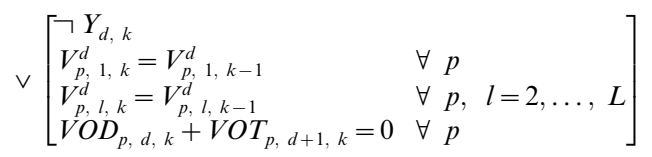

$$
\begin{aligned}
& k=2, \ldots, K
\end{aligned}
$$

Constraints for segment $d(d \neq D)$ are the same as the ones for the first segment, with exception of constraints (Eq. (5)) and (Eq. (8)) that are substituted respectively by constraints (Eq. (17)) and (Eq. (18)).

$$
\begin{aligned}
& \sum_{p=1}^{p} X T_{p, d, k}=X S_{d, k} \quad \forall k, \quad d>1 \\
& X V_{p, l, k}^{d} \geqslant X T_{p, d, k} \quad \forall p, k, \quad d>1, \quad l=1
\end{aligned}
$$

Constraints for the last segment $(d=D)$ are the same as the ones for generic intermediate segments, with exception of constraints (Eq. (12)) and (Eqs. (13a) and (13b)) that are substituted respectively by constraints (Eq. (19)) and (Eqs. (20a) and (20b)). As for the disjunctive representation, $V O T_{p, d+1, k}$ variables in the third equation of every disjunctive term of Eq. (16a) and Eq. (16b) should be removed.

$$
\begin{aligned}
& \sum_{p=1}^{p} X D_{p, d, k}=X S_{d, k} \quad \forall k, \quad d=D \\
& X D_{p, d, k} \geqslant X V Z E R O_{p, l}^{d}-\left[1-X S_{d, k}\right] \\
& \forall p, \quad d=D, \quad l=L, \quad k=1 \\
& X D_{p, d, k} \geqslant X V_{p, l, k-1}^{d}-\left[1-X S_{d, k}\right] \\
& \forall p, \quad d=D, \quad l=L, \quad k=2, \ldots, K
\end{aligned}
$$

Note that this is a convex-hull formulation, although variables $X D_{p, d, k}$ and $X T_{p, d, k}$ are not disaggregated. For this case, a disaggregation of these ones would be redundant, because when a segment $d$ is not fed, all of its outlets assume values equal to zero.

Pinto and Grossmann (1998) and Pinto et al. (2000) describe many approaches for modeling transitions in scheduling systems. Constraints (Eq. (21)) and (Eq. (22)) model transitions for the present case. Note that it is only necessary to verify transitions between the first and second packs of each segment $d$.

$T Y_{p, p^{\prime}, k}^{d} \geqslant X V_{p, 1, k}^{d}+X V_{p^{\prime}, 2, k}^{d}-1$

$\left\{\forall p, p^{\prime}, d \mid \in T S_{p, p^{\prime}}\right\}, \quad \forall k$

$T Y_{p, p^{\prime}, k}^{d}=0 \quad\left\{\forall p, p^{\prime}, d \mid \in F S_{p, p^{\prime}}\right\}, \quad \forall k$

The constraints at depot $d$ follow the same logic as the ones described for the refinery. Moreover, demands must be exactly met, as shown in Eq. (27). 


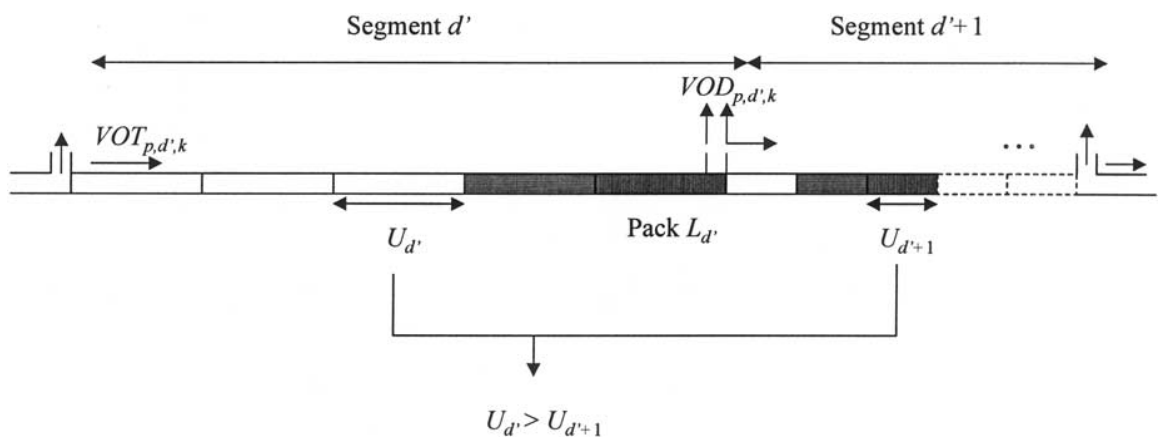

Fig. 3. Pipeline system with lots of different sizes.
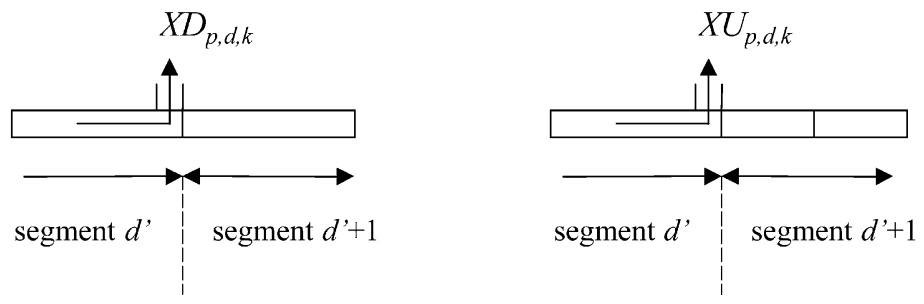

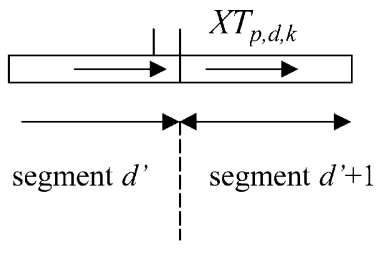

Formulation M1

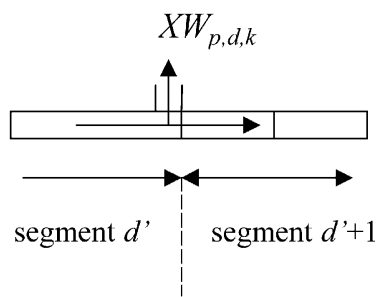

Formulation M2

Fig. 4. Decision variables for the proposed formulations.

$$
\begin{aligned}
& V D_{p, d, k}=V D Z E R O_{p, d}+V O D_{p, d, k}-V O M_{p, d, k} \\
& \forall p, d, \quad k=1 \\
& V D_{p, d, k}=V D_{p, d, k-1}+V O D_{p, d, k}-V O M_{p, d, k} \\
& \forall p, d, \quad k=2, \ldots, K \\
& V D M I N_{p, d, k} \leqslant V D_{p, d, k} \leqslant V D M A X_{p, d, k} \\
& \quad \forall p, d, k \\
& V O M_{p, d, k} \leqslant U M_{p, d, k} \quad \forall p, d, k \\
& \sum_{k=1}^{K} V O M_{p, d, k}=D E M_{p, d} \quad \forall p, d
\end{aligned}
$$

\subsection{Objective function}

The total operational cost is given by Eq. (28). The terms in brackets represent inventory costs at the refinery and depots, respectively. The third term refers to the pumping costs and finally the last one accounts for product transitions.

$$
\begin{aligned}
C= & {\left[\sum_{p=1}^{P} \sum_{k=1}^{K} C E R_{p} \times V R_{p, k}+\sum_{p=1}^{P} \sum_{d=1}^{D} \sum_{k=1}^{K} C E D_{p, d}\right.} \\
& \left.\times V D_{p, d, k}\right] \delta \\
+\sum_{p=1}^{P} & \sum_{d=1}^{D} \sum_{k=1}^{K} C P_{p, d, k} \times V O D_{p, d, k}+\sum_{p=1}^{P} \sum_{p=1}^{P} \sum_{d=1}^{D} \\
& \times \sum_{k=1}^{K} \operatorname{CONTACT}_{p, p^{\prime}} \times T Y_{p, p^{\prime}, k}^{d}
\end{aligned}
$$

It is important to note that the objective function could include a revenue term and therefore profit would be maximized. The only required change in the model equations is to relax Eq. (27) to an inequality constraint that would impose a minimum demand for each product in the markets.

\subsection{Model M2 - packs of different volumetric capacity}

The formulation shown in item 3.2 represents pipelines composed by packs of equal volumetric capacity, 
according to Fig. 2. In this item, a pipeline system composed by packs of different volumetric sizes is ment $d^{\prime}$ (Vecchietti \& Grossmann, 2000).

$$
\begin{aligned}
& {\left[\begin{array}{l}
Y_{d^{\prime}, k} \\
V_{p, 1,1}^{d^{d^{\prime}}}=\operatorname{VOT}_{p, d^{\prime}, 1} \\
V_{p, l, 1}^{d^{\prime}}=V Z E R O_{p, l-1}^{d^{\prime}} \\
{\left[\begin{array}{l}
Z_{d^{\prime}, k}^{d^{d^{\prime}+1}}=V Z E R O_{p, L}^{d^{\prime}}-V O D_{p, d^{\prime}, 1}
\end{array}\right] \vee\left[\begin{array}{l}
\neg Z_{d^{\prime}, k} \\
V O D_{p, d^{\prime}, k}=V Z E R O_{p, L}^{d^{\prime}}
\end{array}\right] \forall p}
\end{array}\right]} \\
& \vee\left[\begin{array}{lll}
\neg Y_{d^{\prime}, k} & \\
V_{p, 1,1}^{d^{\prime}}=V Z E R O_{p, 1}^{d^{\prime}} & \forall p \\
V_{p, l, 1}^{d^{\prime}}=V Z E R O_{p, l}^{d^{\prime}} & \forall p, l=2, \ldots, L \\
V O D_{p, d^{\prime}, 1}=0 & \forall p
\end{array}\right] \\
& k=1
\end{aligned}
$$

addressed. The formulations proposed in item 3.2 tend to generate problems that are computationally intractable, especially when pipeline segments have distinct capacities. Another major drawback is that at most one unloading operation may be performed at each time interval.

According to Figs. 3 and 4, the pipeline system presents the following operational possibilities, related to segments $d^{\prime}$ and $d^{\prime}+1$ :

- Segment $d^{\prime}$ is not fed by its predecessor. In this case, all products remain at the same pack in which they were initially allocated. Consequently, segment $d^{\prime}+1$ also remains inactive. This possibility corresponds to $X U_{p, d^{\prime}, k}=X W_{p, d^{\prime}, k}=0$, as shown in Fig. 4;

- Segment $d^{\prime}$ is fed by its predecessor. In this case, derivatives inside this segment are transferred. For the product allocated at the last pack of segment $d^{\prime}$ denoted as $L_{d^{\prime}}$, two destinations arise:

- This product is completely transferred to depot $d^{\prime}$. In this case, segment $d^{\prime}+1$ also remains inactive. This possibility corresponds to $X U_{p, d^{\prime}, k}=1$ and $X W_{p, d^{\prime}, k}=0$, as shown in Fig. 4;

- This derivative is sent partially to depot $d^{\prime}$ and to segment $d^{\prime}+1$. Consequently, products inside segment $d^{\prime}+1$ are also displaced. Note that for this case, depot $d^{\prime}$ receives an amount equal to $\left(U_{d^{\prime}}-U_{d^{\prime}+1}\right)$. The overall outlet amounts of subsequent depots must sum up $U_{d^{\prime}+1}$. This possibility corresponds to $X U_{p, d^{\prime}, k}=0$ and $X W_{p, d^{\prime}, k}=1$, as shown in Fig. 4.

This new configuration allows more than one simultaneous unloading operation from the pipeline. The sum of all depot outlets must be equal to the pipeline feed provided by the refinery in order to keep overall mass balance. This pipeline system can be initially modeled by embedded disjunctions (Eqs. (29a) and (29b)) for seg-

$$
\begin{aligned}
& {\left[\begin{array}{ll}
Y_{d^{\prime}, k} \\
V_{p, 1, k}^{d^{\prime}}=V O T_{p, d^{\prime}, k} & \forall p \\
V^{d^{\prime}}, l, k=V^{d^{\prime}}, 1-1, k-1 & \forall p, l \\
\Gamma Z
\end{array}\right.} \\
& \begin{array}{l}
p, 1, k=V O T_{p, d^{\prime}, k} \\
V_{p, l, k}^{d^{\prime}}=V_{p, l-1, k-1}^{d^{\prime}}
\end{array} \quad \forall p, \quad l=2, \ldots, L \\
& {\left[\begin{array}{l}
p, l, k=V_{p, l-1, k-1} \\
{\left[\begin{array}{l}
Z_{d^{\prime}, k}^{d^{\prime}+1} \\
V_{p, 1, k}^{d^{\prime}+1}=V_{p, L, k-1}^{d^{\prime}}-V O D_{p, d^{\prime}, k}
\end{array}\right] \vee\left[\begin{array}{l}
\neg Z_{d^{\prime}, k} \\
V O D_{p, d^{\prime}, k}=V_{p, L, k-1}^{d^{\prime}}
\end{array}\right] \forall p}
\end{array}\right.} \\
& \vee\left[\begin{array}{ll}
\neg Y_{d^{\prime}, k} & \\
V_{p, 1,1}^{d^{\prime}}=V_{p, 1, k-1}^{d^{\prime}} & \forall p \\
V_{p, l, 1}^{d^{\prime}}=V_{p, l, k-1}^{d^{\prime}} & \forall p, \quad \forall=2, \ldots, L \\
V O D_{p, d^{\prime}, k}=0 & \forall p
\end{array}\right] \\
& k=2, \ldots, K
\end{aligned}
$$

For this case, the logical relationships are related to the Boolean variables $Y_{d^{\prime}, k}$ and $Z_{d^{\prime}, k}$. The first one indicates that if segment $d^{\prime}$ is under product transference. The last one indicates that if product allocated at $L_{d^{\prime}}$ (with volume $V_{p, L, k-1}^{d}$ ) is sent partially to depot $d^{\prime}$ $\left(V O D_{p, d^{\prime}, k}\right)$ and to segment $d^{\prime}+1\left(V_{p, d^{\prime}+1,1, k}\right)$. This occurs if both Boolean variables are true. If only $Y_{d^{\prime}, k}$ is set true, the amount of such derivative is completely sent to depot $d^{\prime}\left(V O D_{p, d^{\prime}, k}=V_{p, d^{\prime}, L, k-1}\right)$. If both variables are false, segments $d^{\prime}$ and $d^{\prime}+1$ become inactive $\left(V O T_{p, d^{\prime}, k}=0\right.$ and $\left.V O D_{p, d^{\prime}, k}=0\right)$.

The transformation of disjunctions (Eqs. (29a) and (29b)) into mixed-integer constraints is similar to the procedure developed in item 3.2. The system is modeled using the convex-hull formulation (Raman \& Grossmann, 1994). As in the previous model, Boolean variable $Y_{d^{\prime}, k}$ is associated to $X S_{d^{\prime}, k}$, whereas $Z_{d^{\prime}, k}$ is disaggregated into $X W_{p, d^{\prime}, k}$ and $X U_{p, d^{\prime}, k}$. Constraints for segment $d^{\prime}$ are listed below.

$$
\begin{aligned}
& V O T_{p, d^{\prime}, k}=X T_{p, d^{\prime}, k} \times U_{d^{\prime}} \quad \forall p, k \\
& \sum_{p=1}^{P} X T_{p, d^{\prime}, k}=X S_{d^{\prime}, k} \quad \forall k \\
& X S_{d^{\prime}, k} \leqslant 1 \quad \forall k \\
& V_{p, l, k}^{d^{\prime}}=X V_{p, l, k}^{d^{\prime}} \times U_{d^{\prime}} \quad \forall p, l, k
\end{aligned}
$$


$\sum_{p=1}^{P} X V_{p, l, k}^{d^{\prime}}=1 \quad \forall l, k$

$X V_{p, 1, k}^{d^{\prime}} \geqslant X T_{p, d^{\prime} k} \quad \forall p, k$

$X V_{p, l, 1}^{d^{\prime}} \geqslant X V Z E R O_{p, l-1}^{d^{\prime}}-\left[1-X S_{d^{\prime}, 1}\right]$

$\forall p, \quad l=2, \ldots, L$

$X V_{p, l, k}^{d^{\prime}} \geqslant X V_{p, l-1, k-1}^{d^{\prime}}-\left[1-X S_{d^{\prime}, k}\right]$

$\forall p, \quad l=2, \ldots, L, \quad k=2, \ldots, K$

$X V_{p, l, 1}^{d} \geqslant X V Z E R O_{p, l}^{d^{\prime}}-X S_{d^{\prime}, 1} \quad \forall p$,

$\forall p, l, k=2, \ldots, K$ $V O D_{p, d^{\prime}, k}=X W_{p, d^{\prime}, k} \times\left[U_{d^{\prime}}-U_{d^{\prime}+1}\right]+X U_{p, d^{\prime}, k} \times U_{d^{\prime}}$
$\quad \forall p, k$

$\sum_{p=1}^{P}\left[X W_{p, d^{\prime}, k}+X U_{p, d^{\prime}, k}\right]=X S_{d^{\prime}, k} \quad \forall p, k$

$X W_{p, d^{\prime}, 1}+X U_{p, d^{\prime}, 1} \geqslant X V Z E R O_{p, d^{\prime}, L}-\left[1-X S_{d, k}\right]$ $\forall p$

$X W_{p, d^{\prime}, k}+X U_{p, d^{\prime}, k} \geqslant X V_{p, d^{\prime}, L, k-1}-\left[1-X S_{d, k}\right]$

$\forall p, k=2, \ldots, K$

$X V_{p, d^{\prime}+1,1, k} \geqslant X W_{p, d^{\prime}, k} \quad \forall p, k$

$\sum_{p=1}^{P} X W_{p, d^{\prime}, k}=X S_{d^{\prime}+1, k} \quad \forall k$

All constraints related to the segment feed (first pack), contents of packs and product transference remain the same, except for parameter $U$ that is replaced by $U_{d^{\prime}}$ in constraint (Eq. (30)). Constraint (Eq. (31)) presents the possibilities of destination related to product allocated at pack $L_{d^{\prime}}$. Variable $X W_{p, d^{\prime}, k}$ is activated if this derivative is partially sent to depot $d^{\prime}$ and to segment $d^{\prime}+1$, whereas $X U_{p, d^{\prime}, k}$ is only valid if the referred product is totally sent to depot $d^{\prime}$. Constraint (Eq. (32)) states that one of these variables must be activated if segment $d^{\prime}$ is under product transference. Constraint (Eqs. (33a) and (33b)) activates only the variables that are related to product that is allocated at pack $L_{d^{\prime}}$. Constraint (Eq. (34)) models the content of the first pack of segment $d^{\prime}+1$. Note that $X W_{p, d^{\prime}, k}$ automatically activates product transference at segment $d^{\prime}+1$, as shown by constraint (Eq. (35)).

Constraints (Eqs. (36a) and (36b)) and (Eqs. (37a) and (37b)) provide an alternative representation for (Eqs. (33a) and (33b)) and (Eq. (34)). Constraints (Eq. (36a)) and (Eq. (36b)) allow transfer to segment $d^{\prime}+1$ only for the product that is contained in the last pack of the previous segment, whereas Eqs. (37a) and (37b) controls product transfer if it is partially sent to $d^{\prime}+1$.

$$
\begin{aligned}
& X W_{p, d^{\prime}, 1}+X U_{p, d^{\prime}, 1} \leqslant X V Z E R O_{p, L}^{d^{\prime}} \quad \forall p \\
& X W_{p, d^{\prime}, k}+X U_{p, d^{\prime}, k} \leqslant X V_{p, L, k-1}^{d^{\prime}} \\
& \forall p, \quad k=2, \ldots, K
\end{aligned}
$$

\begin{tabular}{|c|c|}
\hline Operational system & Constraints \\
\hline Refinery & Eqs. (1a), (1b), (2) and (3) \\
\hline $\begin{array}{l}\text { First segment of the pi- } \\
\text { peline }\end{array}$ & $\begin{array}{l}\text { Eqs. }(5)-(8),(9 a),(9 b),(10 a),(10 b),(11), \\
(12),(13 a),(13 b),(14),(15 a) \text { and }(15 b)\end{array}$ \\
\hline $\begin{array}{l}\text { Intermediate segments of } \\
\text { the pipeline }\end{array}$ & $\begin{array}{l}\text { Eqs. (6) and (7), Eqs. (9a), (9b), (10a), } \\
(10 b),(11),(12),(13 a),(13 b),(14),(15 a) \\
\text { and }(15 b), \text { Eqs. (17) and (18) }\end{array}$ \\
\hline $\begin{array}{l}\text { Terminal segment of the } \\
\text { pipeline }\end{array}$ & $\begin{array}{l}\text { Eqs. (6) and (7), Eqs. (9a), (9b), (10a), } \\
(10 b) \text { and (11), Eqs. (14), (15a) and (15b), } \\
\text { Eqs. (17)-(19), (20a) and (20b) }\end{array}$ \\
\hline Sequencing constraints & Eqs. (21) and (22) \\
\hline Depots & Eqs. (23)-(27) \\
\hline Integer cut & Eqs. (38) and (39) \\
\hline Objective function & Eq. (28) \\
\hline
\end{tabular}

Table 1

Summary of model M1

\begin{tabular}{|c|c|}
\hline Operational system & Constraints \\
\hline Refinery & Eqs. (1a), (1b), (2) and (3) \\
\hline First segment of the pipeline & $\begin{array}{l}\text { Eqs. }(5)-(8),(9 a),(9 b),(10 a),(10 b), \\
(11),(12),(13 a),(13 b),(14),(15 a) \text { and } \\
(15 b)\end{array}$ \\
\hline $\begin{array}{l}\text { Intermediate segments of the } \\
\text { pipeline }\end{array}$ & $\begin{array}{l}\text { Eqs. (6) and (7), Eqs. (9a), (9b), (10a), } \\
(10 b),(11),(12),(13 a),(13 b),(14), \\
(15 a) \text { and }(15 b), \text { Eqs. (17) and (18) }\end{array}$ \\
\hline $\begin{array}{l}\text { Segments with packs of differ- } \\
\text { ent volumetric capacities }\end{array}$ & $\begin{array}{l}\text { Eqs. (6) and (7), Eqs. (9a), (9b), (10a), } \\
(10 b) \text { and (11), Eqs. }(17) \text { and (18), } \\
\text { Eqs. (30)-(32), Eqs. }(35),(36 a), \\
(36 b),(37 a) \text { and (37b) }\end{array}$ \\
\hline $\begin{array}{l}\text { Terminal segment of the pipe- } \\
\text { line }\end{array}$ & $\begin{array}{l}\text { Eqs. (6) and (7), Eqs. (9a), (9b), (10a), } \\
(10 b) \text { and }(11) \text {, Eqs. }(14),(15 a) \text { and } \\
(15 b) \text {, Eqs. }(17)-(19),(20 a) \text { and }(20 b)\end{array}$ \\
\hline Sequencing constraints & Eqs. (21) and (22) \\
\hline Depots & Eqs. (23)-(27) \\
\hline Integer cut & Eqs. (38) and (39) \\
\hline Objective function & Eq. (28) \\
\hline
\end{tabular}

Table 2

Summary of model M2

$X V_{p, 1,1}^{d^{\prime}+1} \geqslant X V Z \operatorname{ERO}_{p, L}^{d^{\prime}}-\left[1-X W_{p, d, 1}\right] \quad \forall p$

$X V_{p, 1, k}^{d^{\prime}+1} \geqslant X V_{p, L, k-1}^{d^{\prime}}-\left[1-X W_{p, d, k}\right] \quad \forall p, k$

\subsection{Integer cut}

An integer cut constraint is proposed in order to reduce the combinatorial search for models M1 and M2. This constraint is based on the minimum number of times that a depot $d$ must receive product $p$ from the pipeline along the time horizon. This condition depends on the demands determined by the consumer market and on the initial inventory of each depot for each derivative. In order to implement this constraint, a new parameter must be defined, according to Eq. (38).

$X D M I N_{p, d}=$ 
Table 3

Data for example 1

\begin{tabular}{|c|c|c|c|c|c|}
\hline \multirow[t]{3}{*}{ Product } & \multicolumn{2}{|l|}{ Inventory costs } & \multicolumn{2}{|c|}{ Maximum/minimum inventory levels } & \\
\hline & Refinery & Depots & Refinery & Depots & \\
\hline & $\begin{array}{l}C E R_{p} \\
\left(\$ / \mathrm{m}^{3} \mathrm{~h}\right)\end{array}$ & $\begin{array}{l}C E D_{p, d} \\
\left(\$ / \mathrm{m}^{3} \mathrm{~h}\right)\end{array}$ & $\begin{array}{l}V R M A X_{p, k} / V R M I N_{p, k} \\
\left(\times 10^{-2} \mathrm{~m}^{3}\right)\end{array}$ & $\begin{array}{l}V D M A X_{p, d, k} / V D M I N_{p, d, k} \\
\left(\times 10^{-2} \mathrm{~m}^{3}\right)\end{array}$ & \\
\hline$p=1$ & 0.070 & 0.100 & $1200 / 270$ & $400 / 90$ & \\
\hline$p=2$ & 0.080 & 0.155 & $1200 / 270$ & $400 / 90$ & \\
\hline$p=3$ & 0.095 & 0.200 & $350 / 50$ & $70 / 10$ & \\
\hline \multirow[t]{3}{*}{$p=4$} & 0.090 & 0.170 & $1200 / 270$ & $400 / 90$ & \\
\hline & \multicolumn{3}{|c|}{ Initial condition of segments } & & \\
\hline & $\begin{array}{l}\operatorname{VZERO} O_{p, 1, l} / X V Z E R O_{p, 1, l} \\
\left(\times 10^{-2} \mathrm{~m}^{3}\right)\end{array}$ & $\begin{array}{l}\operatorname{VZERO} O_{p, 2, l} / X V Z E R O_{p, 2, l} \\
\left(\times 10^{-2} \mathrm{~m}^{3}\right)\end{array}$ & $\begin{array}{l}V Z E R O_{p, 3, l} / X V Z E R O_{p, 3, l} \\
\left(\times 10^{-2} \mathrm{~m}^{3}\right)\end{array}$ & & \\
\hline$p=1$ & $25 / 1(l=1,2,3)$ & $0 / 0$ & $25 / 1(l=3,4)$ & & \\
\hline$p=2$ & $25 / 1(l=4)$ & $25 / 1(l=1,2,3,4)$ & $25 / 1(l=1,2)$ & & \\
\hline$p=3$ & $0 / 0$ & $0 / 0$ & $0 / 0$ & & \\
\hline \multirow{3}{*}{$p=4$} & $0 / 0$ & $0 / 0$ & $0 / 0$ & & \\
\hline & \multicolumn{2}{|c|}{ Initial condition of segments } & \multirow{2}{*}{\multicolumn{2}{|c|}{ Initial inventory at the refinery }} & \\
\hline & $\begin{array}{l}\operatorname{VZERO} O_{p, 4, l} / X V Z E R O_{p, 4, l} \\
\left(\times 10^{-2} \mathrm{~m}^{3}\right)\end{array}$ & 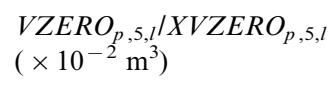 & & & \\
\hline$p=1$ & $25 / 1(l=1,2,3)$ & $25 / 1(1=1,2,3)$ & 500 & & \\
\hline$p=2$ & $25 / 1(l=4)$ & $0 / 0$ & 520 & & \\
\hline$p=3$ & $0 / 0$ & $0 / 0$ & 210 & & \\
\hline \multirow[t]{3}{*}{$p=4$} & $0 / 0$ & $0 / 0$ & 515 & & \\
\hline & \multicolumn{2}{|l|}{ Initial inventory of depots } & & & \\
\hline & $\begin{array}{l}\text { VDZERO } \\
\left(\times 10^{-2} \mathrm{~m}^{3}\right)\end{array}$ & $\begin{array}{l}\text { VDZERO } \\
\left(\times 10^{-2} \mathrm{~m}^{3}\right)\end{array}$ & $\begin{array}{l}\text { VDZERO } \\
\left(\times 10^{-2} \mathrm{~m}^{3}\right)\end{array}$ & $\begin{array}{l}\operatorname{VDZERO} O_{p, 4} \\
\left(\times 10^{-2} \mathrm{~m}^{3}\right)\end{array}$ & $\begin{array}{l}\operatorname{VDZERO} O_{p, 5} \\
\left(\times 10^{-2} \mathrm{~m}^{3}\right)\end{array}$ \\
\hline$p=1$ & 190 & 230 & 200 & 240 & 190 \\
\hline$p=2$ & 180 & 210 & 180 & 180 & 180 \\
\hline$p=3$ & 50 & 65 & 60 & 60 & 60 \\
\hline$p=4$ & 120 & 140 & 190 & 190 & 170 \\
\hline
\end{tabular}

$\max \left\{0,\left\lceil\frac{D E M_{p, d}-\left(V D Z E R O_{p, d}-V D M I N_{p, d}\right)}{U_{d}}\right\rceil\right\} \forall p, d$

where $\lceil$.$\urcorner denotes the upper integer part operator.$ Note that in (Eq. (38)) index $k$ is removed from parameter $V D M I N_{p, d, k}$. This is possible since this parameter remains constant during the time horizon. The integer cut constraint is shown in Eq. (39).

$\sum_{k=1}^{K} X D_{p, d, k} \geqslant X D M I N_{p, d} \quad \forall p, d$

\subsection{Summary of models M1 and M2}

Tables 1 and 2 summarize models M1 and M2. In model M2, constraints (Eqs. (36a) and (36b)) and (Eqs. (37a) and (37b)) are imposed in place of (Eqs. (33a) and (33b)) and (Eq. (34)).
It is important to note that the number of binary variables is unaffected by the number of packs at each segment. The binary variables are $X R_{p, k}$ and those described in Fig. 4. All these depend on the number of products $(p)$, depots $(d)$ and time intervals $(k)$. With exception of the objective function variable $(C)$, all continuous variables are non-negative.

\section{Case studies}

In this section, two examples are presented. Example 1 utilizes the formulation of packs with equal volumetric capacity (M1) and example 2 is based on a real-world system that considers different pack sizes (model M2). GAMS modeling language (Brooke, Kendrick, \& Meeraus, 2000) was used to implement the MILP model that was solved with CPLEX (Ilog, 1999) in both examples in a PC platform with Pentium II $400 \mathrm{MHz}$ processor. 
Table 4

Sequencing costs and demands for example 1

\begin{tabular}{|c|c|c|c|c|c|c|c|c|c|}
\hline & \multicolumn{4}{|c|}{$C O N T A C T_{p, p^{\prime}}\left(\times 10^{-2} \$\right)$} & \multicolumn{5}{|c|}{$D E M_{p, d}\left(\times 10^{-2} \mathrm{~m}^{3}\right)$} \\
\hline & $\begin{array}{l}p^{\prime}= \\
1\end{array}$ & $\begin{array}{l}p^{\prime}= \\
2\end{array}$ & $\begin{array}{l}p^{\prime}= \\
3\end{array}$ & $\begin{array}{l}p^{\prime}= \\
4\end{array}$ & $\begin{array}{l}d= \\
1\end{array}$ & $\begin{array}{l}d= \\
2\end{array}$ & $\begin{array}{l}d= \\
3\end{array}$ & $\begin{array}{l}d= \\
4\end{array}$ & $\begin{array}{l}d= \\
5\end{array}$ \\
\hline $\begin{array}{l}p= \\
1\end{array}$ & 0 & 30 & 37 & 35 & 100 & 110 & 120 & 120 & 150 \\
\hline $\begin{array}{l}p= \\
2\end{array}$ & 30 & 0 & $X$ & 38 & 70 & 90 & 100 & 80 & 100 \\
\hline $\begin{array}{l}p= \\
3\end{array}$ & 37 & $X$ & 0 & $\mathrm{X}$ & 60 & 40 & 40 & 0 & 20 \\
\hline $\begin{array}{l}p= \\
4\end{array}$ & 35 & 38 & $X$ & 0 & 60 & 50 & 50 & 50 & 50 \\
\hline
\end{tabular}

Table 5

Pumping costs for example 1

\begin{tabular}{|c|c|c|c|c|c|}
\hline \multirow[t]{2}{*}{ Time intervals $(k)$} & \multicolumn{5}{|c|}{$p=1\left(C P_{1, d, k}\left(\times \$ / \mathrm{m}^{3}\right)\right)$} \\
\hline & $d=1$ & $d=2$ & $d=3$ & $d=4$ & $d=5$ \\
\hline $1-3,6-8,11-15$ & 3.5 & 4.5 & 5.5 & 6.0 & 6.9 \\
\hline $4-5,9-10$ & 17.5 & 22.5 & 27.5 & 30.0 & 34.5 \\
\hline \multirow[t]{2}{*}{ Time intervals $(k)$} & \multicolumn{5}{|c|}{$p=2\left(C P_{2, d, k}\left(\times \$ / \mathrm{m}^{3}\right)\right)$} \\
\hline & $d=1$ & $d=2$ & $d=3$ & $d=4$ & $d=5$ \\
\hline $1-3,6-8,11-15$ & 3.6 & 4.6 & 5.6 & 6.2 & 7.3 \\
\hline $4-5,9-10$ & 18.0 & 23.0 & 28.0 & 31.0 & 36.5 \\
\hline \multirow[t]{2}{*}{ Time intervals $(k)$} & \multicolumn{5}{|c|}{$p=3\left(C P_{3, d, k}\left(\times \$ / \mathrm{m}^{3}\right)\right)$} \\
\hline & $d=1$ & $d=2$ & $d=3$ & $d=4$ & $d=5$ \\
\hline $1-3,6-8,11-15$ & 4.8 & 5.7 & 6.8 & 7.9 & 8.9 \\
\hline $4-5,9-10$ & 24.0 & 28.5 & 34.0 & 39.5 & 44.5 \\
\hline \multirow[t]{2}{*}{ Time intervals $(k)$} & \multicolumn{5}{|c|}{$p=4\left(C P_{4, d, k}\left(\times \$ / \mathrm{m}^{3}\right)\right)$} \\
\hline & $d=1$ & $d=2$ & $d=3$ & $d=4$ & $D=5$ \\
\hline $1-3,6-8,11-15$ & 3.7 & 4.7 & 5.7 & 6.1 & 7.0 \\
\hline $4-5,9-10$ & 18.5 & 23.5 & 28.5 & 30.5 & 35.0 \\
\hline
\end{tabular}

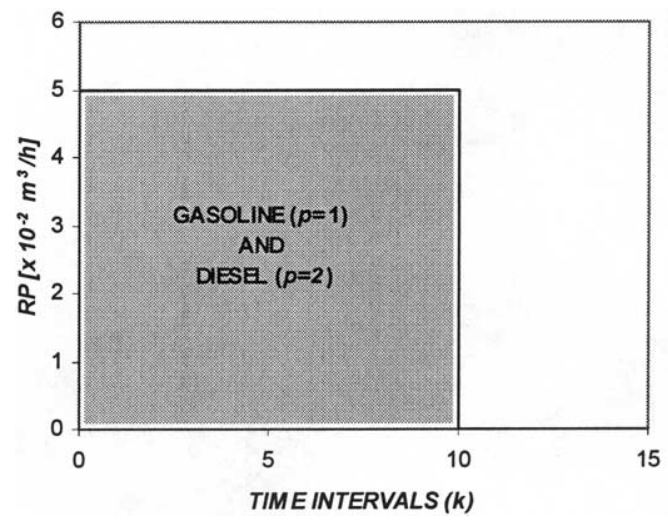

Table 6

Computational data for example 1

\section{Model M1}

Relaxed solution $\left(\$ \times 10^{-2}\right)$

33120.125

Solution $\left(\$ \times 10^{-2}\right)$

CPU time (s)

Nodes visited

34178.625

Continuous variables

10000

Binary variables

3307

4516

Equations

6401

\subsection{Example 1}

Transfer of crude oil and derivatives through pipelines requires electrical energy. Nevertheless, in periods of higher energy demand pumping costs increase. In these time periods, all pipelines should be inoperative, although sometimes this is not possible due to demand requirements for derivatives. Therefore, pumping costs are highly penalized during a few intervals of the time horizon. Example 1 presents a refinery that must distribute four products among five depots through one pipeline. Five segments compose the pipeline system. Segments $1-4$ have a $10000 \mathrm{~m}^{3}$ volumetric capacity and the fifth one contains $7500 \mathrm{~m}^{3}$. This scenario is composed of 15 time intervals with $5 \mathrm{~h}$ each discretized at the pipeline segments in packs of $2500 \mathrm{~m}^{3}$ and at the depots in $2000 \mathrm{~m}^{3}$.

As all packs have $2500 \mathrm{~m}^{3}$ of volumetric capacity, segments 1-4 contain 4 packs each and segment 5 contains only 3. Tables 3-5 show data for example 1 . Inventory bounds and costs at all locations as well as initial conditions of tanks and pipeline segments are illustrated in Table 3, whereas Table 4 shows sequencing

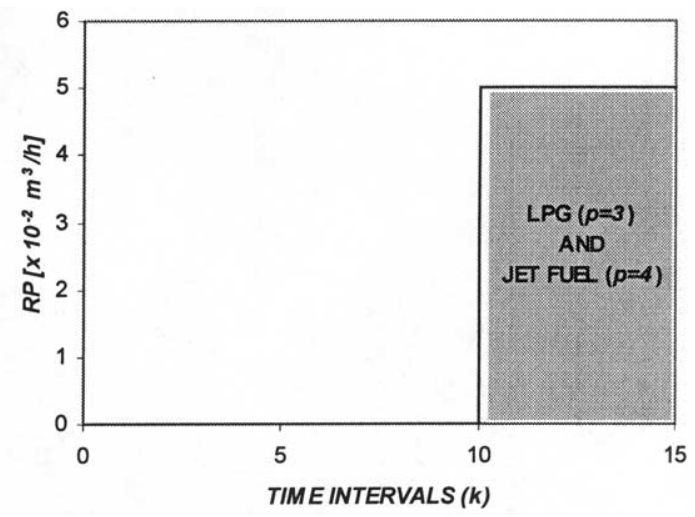

Fig. 5. Production profile in the refinery for examples 1 and 2. 

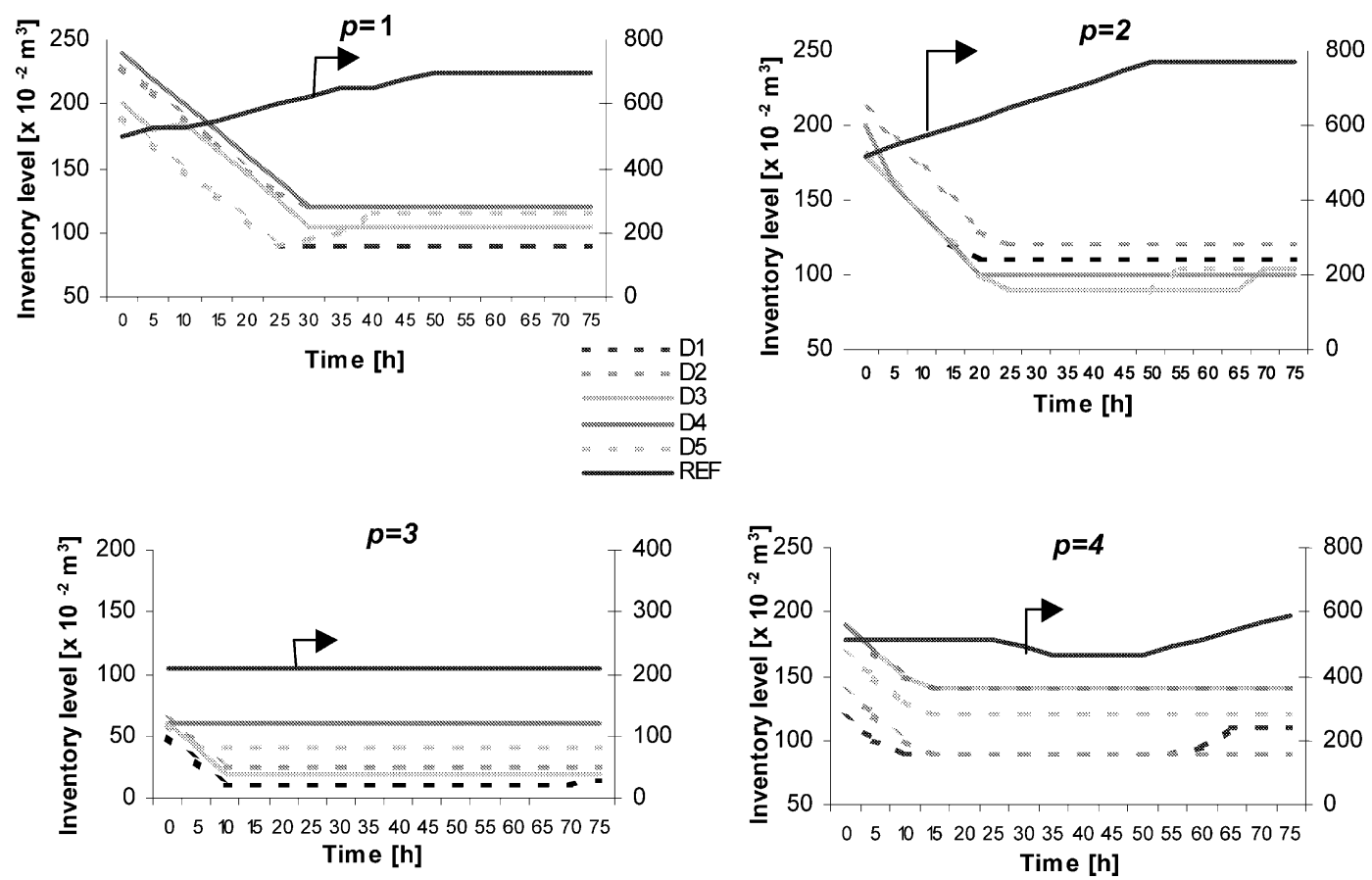

Fig. 6. Inventory levels at the system for example 1.
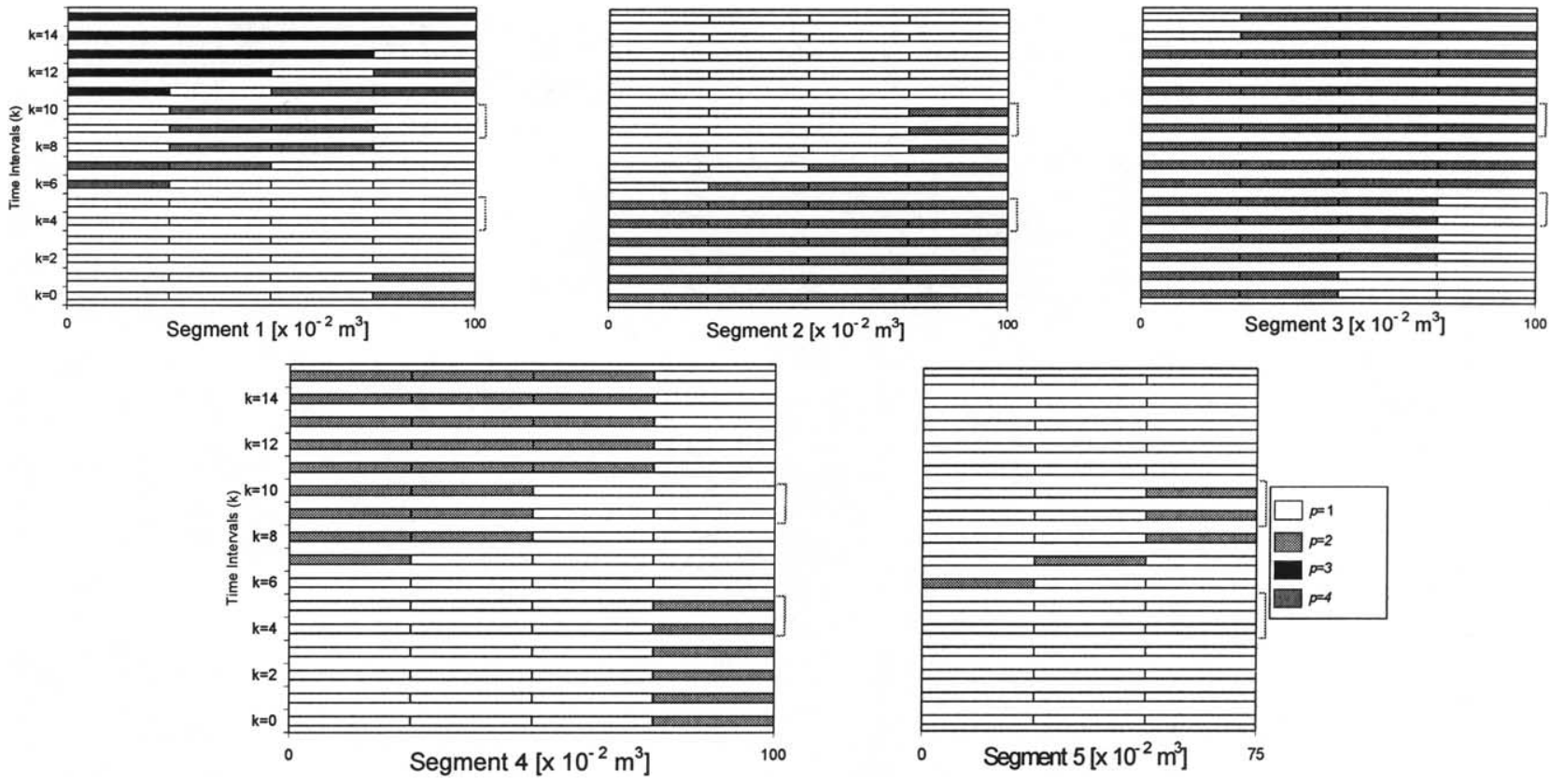

Fig. 7. Pipeline transportation profile for example 1.

costs and product demands. Pumping cost values are given in Table 5 at all time intervals. The production profile in the refinery is given in Fig. 5.

Computational data is listed in Table 6 . Note that the initial gap is of $3.1 \%$, reaching a final optimality gap of less than $1 \%$ within $10000 \mathrm{CPU}$ (s). Overall, there are 600 binary variables; among these 60 binary variables represent the decision of sending products from the refinery to the pipeline at every time and the remaining ones represent transfers to the next segment and to the depots.

Results for this example are shown in Figs. 6 and 7. From Tables 4 and 5, it can be inferred that only the first depot requires that LPG to be sent from the 
Table 7

Pipeline transportation profile for example 1

\begin{tabular}{lll}
\hline Time interval $(k)$ & Active segments & Inactive segments \\
\hline 1 & - & $1,2,3,4,5$ \\
2 & $1,2,3$ & 4,5 \\
3 & - & $1,2,3,4,5$ \\
4 & - & $1,2,3,4,5$ \\
5 & - & $1,2,3,4,5$ \\
6 & $1,2,3,4,5$ & - \\
7 & $1,2,3,4,5$ & - \\
8 & $1,2,3,4,5$ & - \\
9 & - & $1,2,3,4,5$ \\
10 & - & $1,2,3,4,5$ \\
11 & $1,2,3,4,5$ & - \\
12 & 1 & $2,3,4,5$ \\
13 & 1 & $2,3,4,5$ \\
14 & $1,2,3$ & 4,5 \\
15 & 1 & $2,3,4,5$ \\
\hline
\end{tabular}

refinery. In order to fulfill that demand, this product is transferred and drawn only in the first segment, as seen in Fig. 7. From this figure, it can be noted that the pipeline remains inoperative at all time intervals that penalize energy costs.

The analysis of pipeline transportation profile is a complex task due to its magnitude and mainly because not all segments may be under operation at all time intervals. In order to assist the understanding of Fig. 7, Table 7 enumerates segments of the pipeline that are activated at all time intervals. It is important to note that a segment is under operation during time interval $k$ if its profile is displaced from the one at time interval $k-1$. For instance, in Table 7 it can be seen that at $k=2$ segments $1-3$ are under operation whereas 4 and 5 are inactive, which can be verified in Fig. 7.
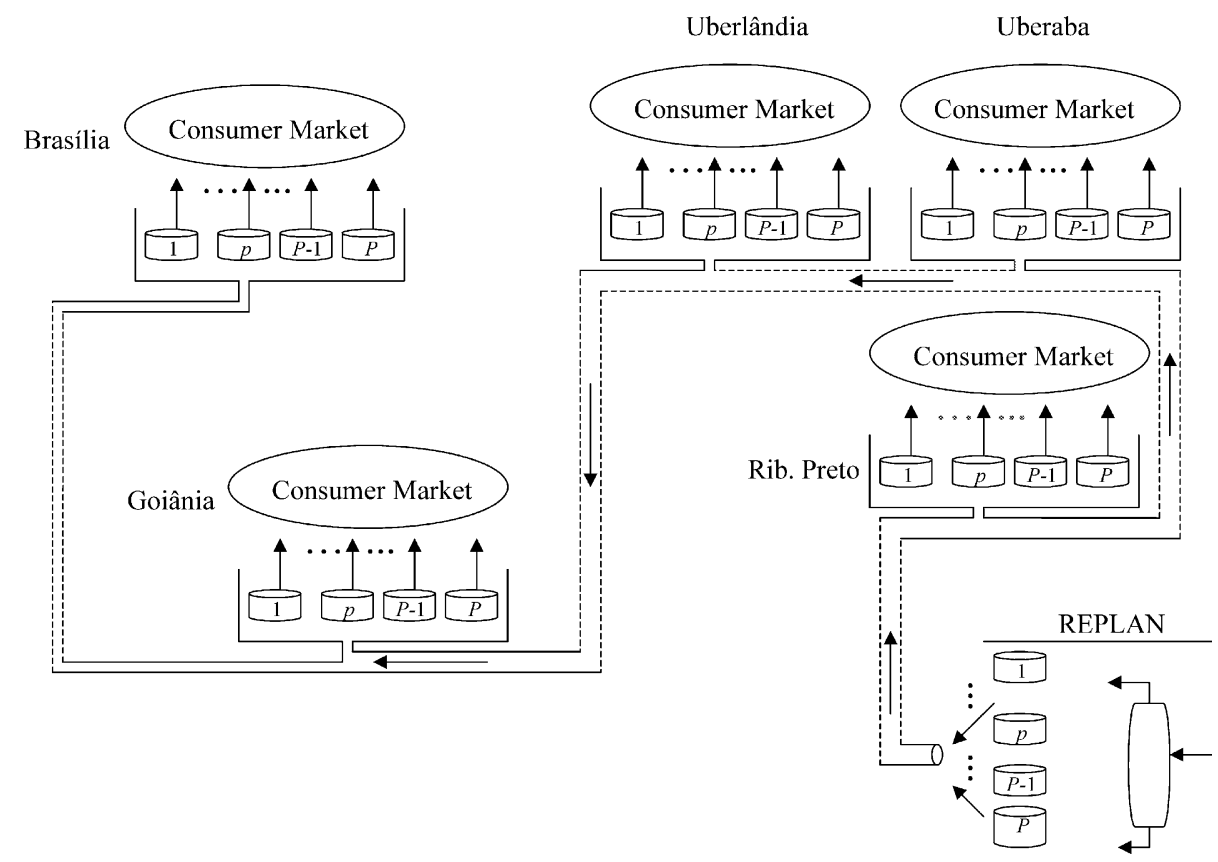

Fig. 8. Operating flowsheet of the distribution system in example 2.

Table 8

Volumetric capacities and lots of the OSBRA pipeline

\begin{tabular}{llllll}
\hline Segment & Actual capacity $\left(\mathrm{m}^{3}\right)$ & Discrete capacity $\left(\mathrm{m}^{3}\right)$ & Difference $(\%)$ & $U_{d}\left(\times 10^{-2} \mathrm{~m}^{3}\right)$ & $L_{d}$ lots \\
\hline REPLAN-Rib. Preto & 39759 & 40000 & 0.61 & 50 & 8 \\
Rib. Preto-Uberaba & 25879 & 25000 & -3.52 & 50 & 5 \\
Uberaba-Uberlândia & 25321 & 25000 & -1.27 & 50 & 5 \\
Uberlândia-Goiânia & 59676 & 60000 & 0.54 & 50 & 12 \\
Goiânia-Brasília & 13739 & 13500 & -1.74 & 27 & 5 \\
\hline
\end{tabular}


Table 9

Capacity bounds and initial condition at refinery

\begin{tabular}{lll}
\hline Product & $\begin{array}{l}\text { Max/min capacities } \\
\operatorname{VRMAX}_{p, k} / \text { VRMIN }_{p, k} \\
\left(\times 10^{-2} \mathrm{~m}^{3}\right)\end{array}$ & $\begin{array}{l}\text { Initial condition } \\
\text { VRZERO }_{p, d} \\
\left(\times 10^{-2} \mathrm{~m}^{3}\right)\end{array}$ \\
\hline Gasoline (1) & $2250 / 400$ & 1000 \\
Diesel (2) & $2500 / 400$ & 1200 \\
LPG (3) & $300 / 50$ & 100 \\
Jet fuel (4) & $560 / 150$ & 315 \\
\hline
\end{tabular}

\subsection{Example 2}

The Petrobras system that is composed by REPLAN refinery located at Paulínia (SP), by the pipeline OSBRA and five depots located at Ribeirão Preto (SP), Uberaba (MG), Uberlândia (MG), Goiânia (GO) and Brasília (DF) represents an interesting and at the same time challenging problem, as illustrated in Fig. 8. The pipeline extension is of approximately $955 \mathrm{~km}$. Products include diesel oil, gasoline, jet fuel and LPG, which is transported under liquid state. The pipeline feed flow

Table 10

Capacity bounds and initial condition at depots

\begin{tabular}{llll}
\hline Depot & Product & Max/Min capacities $\left(\times 10^{-2} \mathrm{~m}^{3}\right)$ & $\begin{array}{l}\text { Initial condition }\left(\times 10^{-2} \mathrm{~m}^{3}\right) \\
V D Z E R O_{p, d}\end{array}$ \\
\hline Rib. Preto & & VDM $X_{p, d, k} / V D M I N_{p, d, k}$ & 100 \\
& Gasoline (1) & $190 / 50$ & 180 \\
& Diesel (2) & $270 / 90$ & 90 \\
Uberaba & $120 / 20$ & 40 \\
& Jet fuel (4) & $0 / 0$ & 150 \\
& Gasoline (1) & $90 / 30$ & 0 \\
& Diesel (2) & $190 / 50$ & 0 \\
Uberlândia & LPG (3) & $0 / 0$ & 50 \\
& Jet fuel (4) & $0 / 0$ & 180 \\
& Gasoline (1) & $90 / 20$ & 60 \\
& Diesel (2) & $270 / 90$ & 0 \\
Goiânia & LPG (3) & $120 / 20$ & 110 \\
& Jet fuel (4) & $0 / 0$ & 350 \\
& Gasoline (1) & $190 / 50$ & 60 \\
& Diesel (2) & $720 / 150$ & 90 \\
Brasília & LPG (3) & $180 / 20$ & 100 \\
& Jet fuel (4) & $140 / 30$ & 330 \\
& Gasoline (1) & $180 / 50$ & 60 \\
& Diesel (2) & $720 / 150$ & 110
\end{tabular}

Table 11

Parameters for example 2

\begin{tabular}{|c|c|c|c|c|c|c|c|c|c|}
\hline \multirow[t]{2}{*}{ Product } & \multicolumn{2}{|c|}{ Inventory costs $\left(\$ / \mathrm{m}^{3} \mathrm{~h}\right)$} & \multicolumn{2}{|c|}{ Pumping costs $\left(\$ / \mathrm{m}^{3}\right)$} & & & & & \\
\hline & Refinery $C E R_{p}$ & Depots $C E D_{p, d}$ & $C P_{p, 1} / C P_{p, 2}$ & $C P_{p, 3} / C P_{p, 4} / C P_{p, 5}$ & & & & & \\
\hline Gasoline (1) & 0.020 & 0.100 & $3.5 / 4.5$ & $5.5 / 6.0 / 6.9$ & & & & & \\
\hline Diesel (2) & 0.023 & 0.155 & $3.6 / 4.6$ & $5.6 / 6.2 / 7.3$ & & & & & \\
\hline LPG (3) & 0.070 & 0.200 & $4.8 / 5.7$ & $6.8 / 7.9 / 8.9$ & & & & & \\
\hline \multirow[t]{3}{*}{ Jet fuel (4) } & 0.025 & 0.170 & $3.7 / 4.7$ & $5.7 / 6.1 / 7.0$ & & & & & \\
\hline & \multicolumn{4}{|c|}{$C O N T A C T_{p, p^{\prime}}\left(\times 10^{-} 2 \$\right)$} & \multicolumn{5}{|c|}{$D E M_{p, d}\left(\times 10^{-2} \mathrm{~m}^{3}\right)$} \\
\hline & $p^{\prime}=1$ & $p^{\prime}=2$ & $p^{\prime}=3$ & $p^{\prime}=4$ & $d=1$ & $d=2$ & $d=3$ & $d=4$ & $d=5$ \\
\hline$p=1$ & 0 & 30 & 37 & 35 & 0 & 80 & 80 & 130 & 70 \\
\hline$p=2$ & 30 & 0 & $\mathrm{X}$ & 38 & 100 & 0 & 10 & 200 & 270 \\
\hline$p=3$ & 37 & $\mathrm{X}$ & 0 & $\mathrm{X}$ & 20 & 0 & 20 & 50 & 20 \\
\hline$p=4$ & 35 & 38 & $\mathrm{X}$ & 0 & 0 & 0 & 0 & 20 & 50 \\
\hline
\end{tabular}


Table 12

Initial conditions at each pipeline segment

\begin{tabular}{|c|c|c|c|}
\hline Product & $\begin{array}{l}V Z E R O_{p, 1, l} / X V Z E R O_{p, 1, l} \\
\left(\times 10^{-2} \mathrm{~m}^{3}\right)\end{array}$ & $\begin{array}{l}V Z E R O_{p, 2, l} / X V Z E R O_{p, 2, l} \\
\left(\times 10^{-2} \mathrm{~m}^{3}\right)\end{array}$ & $\begin{array}{l}\operatorname{VZERO} O_{p, 3, l} / X V Z E R O_{p, 3, l} \\
\left(\times 10^{-2} \mathrm{~m}^{3}\right)\end{array}$ \\
\hline Gasoline (1) & $0 / 0$ & $25 / 1(l=1,2,3,4,5)$ & $25 / 1(l=1,2,3,4,5)$ \\
\hline Diesel (2) & $25 / 1(l=1,2,3,4,5,6,7,8)$ & $0 / 0$ & $0 / 0$ \\
\hline LPG (3) & $0 / 0$ & $0 / 0$ & $0 / 0$ \\
\hline \multirow[t]{2}{*}{ Jet fuel (4) } & $0 / 0$ & $0 / 0$ & $0 / 0$ \\
\hline & $\begin{array}{l}\operatorname{VZERO} O_{p, 4, l} / X V Z E R O_{p, 4, l} \\
\left(\times 10^{-2} \mathrm{~m}^{3}\right)\end{array}$ & $\begin{array}{l}V Z E R O_{p, 5, l} / X V Z E R O_{p, 5, l} \\
\left(\times 10^{-2} \mathrm{~m}^{3}\right)\end{array}$ & \\
\hline Gasoline (1) & $25 / 1(l=1,2,3,4,9,10,11,12)$ & $0 / 0$ & \\
\hline Diesel (2) & $0 / 0$ & $25 / 1(l=1,2,3,4,5)$ & \\
\hline LPG (3) & $25 / 1(l=5,6,7,8)$ & $0 / 0$ & \\
\hline Jet fuel (4) & $0 / 0$ & $0 / 0$ & \\
\hline
\end{tabular}

rates range from 800 to $1200 \mathrm{~m}^{3} / \mathrm{h}$. The actual volumetric capacities of the pipeline segments as well as their discretized values are given in Table 8. All segments present the same flow rate, with exception of the last one. Correspondingly, there is a reduction in the diameter at that segment in order to maintain a better operating condition.

The tank farm at REPLAN is composed by several tanks for each product that are aggregated in a single tank capacity since all are dedicated to OSBRA pipeline, as listed in Table 9. Some of these are floating roof tanks that require a minimum volume such that the floating device does not touch the tank floor. This minimum volume usually corresponds to $10-15 \%$ of the tank capacity. Exception is made to LPG that is stored in spheres and therefore does not require any strict lower bound. Obviously, all tanks present upper bounds. Table 10 presents all storage data. Another important feature is that not all depots store all products; an example is jet fuel that is stored only in Goiânia and Brasília. The flow rates from the pipeline to the depots are approximately $150 \mathrm{~m}^{3} / \mathrm{h}$, whereas flow rates from all depots to the markets average $70 \mathrm{~m}^{3} / \mathrm{h}$.

Data for this example, including number of products and depots, the set of forbidden product sequences are given in Table 11. Initial conditions of the pipelines are shown in Table 12 and Fig. 5 provides the production profile in the refinery.

In the present example, LPG can only be transferred between two lots of gasoline. Therefore, product sequencing in the pipeline is described in Table 11, where the forbidden sequences are denoted with ' $\mathrm{X}$ '. Note that although the diesel-jet fuel interface is allowed, this sequence is undesirable due to its high transition costs.

From all cost components, inventory costs are the highest due to the large amounts that are stored in the refinery. In decreasing order, storage costs at depots,
Table 13

Computational performance of example 2

\begin{tabular}{ll}
\hline Model M2 & \\
\hline Relaxed solution $\left(\$ \times 10^{-2}\right)$ & 22407.752 \\
Solution $\left(\$ \times 10^{-2}\right)$ & 23995.925 \\
CPU time $(\mathrm{s})$ & 10000 \\
Nodes visited & 2286 \\
Continuous variables & 6316 \\
Binary variables & 420 \\
Equations & 9393
\end{tabular}

pumping costs and transition costs are accounted for in the objective function.

An instance of a 75-h time horizon that is discretized in 5-h intervals is presented. A solution with 5.8\% relative gap was obtained in $10000 \mathrm{CPU}$ (s). Computational performance of the model is given in Table 13 . Note that the number of binary variables is smaller than that in example 1. The reduction occurs because in this example variables $X U_{p, d, k}$ and $X W_{p, d, k}$ can be set as continuous. This is possible because variables $X S_{d, k}$ for $d=4$ and $d=5$ always assume 0 or 1 values, since these relate to binary variables $X T_{p, 4, k}$ and $X D_{p, 5, k}$, respectively (see constraints (Eq. (17)) and (Eq. (19))). Therefore, from constraints (Eqs. (33a), (33b) and (34)) or (Eqs. (36a), (36b), (37a) and (37b)) $X U_{p, 4, k}$ and $X W_{p, 4, k}$ may be defined as continuous.

Fig. 9 shows that in the beginning of the operation all depots supply their respective markets by simply reducing their inventory levels. According to Fig. 10, it can be seen that the pipeline operates during the following intervals: $k=\{3,4,5,7,8,9,12,14,15\}$. On the other hand, note from Fig. 9 that inventory levels do not increase during the intervals that the pipeline is inoperative.

For $k=5$, there is an increase in the inventory level of gasoline at the Uberaba depot (see Fig. 9) that results from its transfer through the first three pipeline seg- 

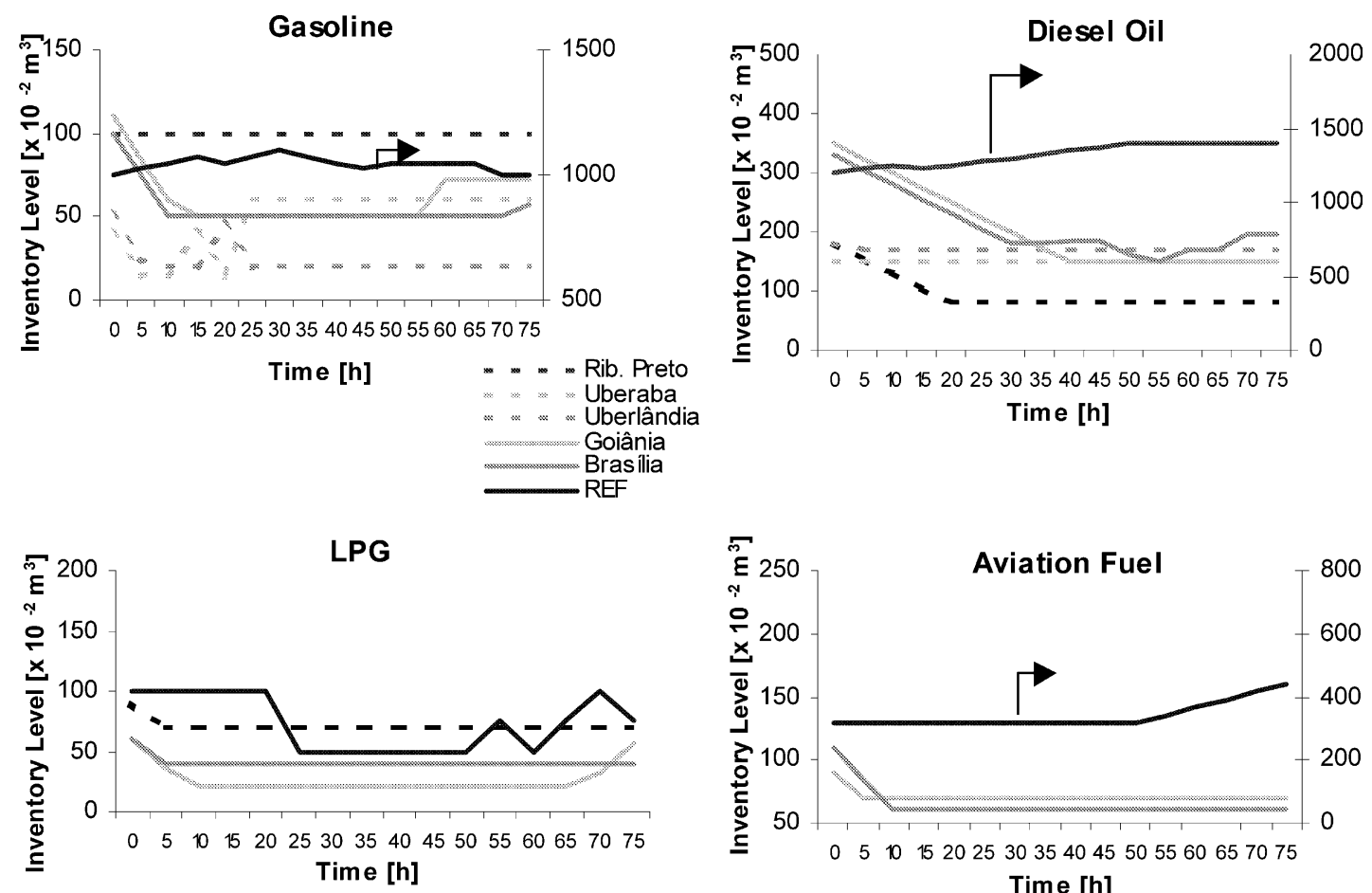

Fig. 9. Inventory levels at the system for example 2.
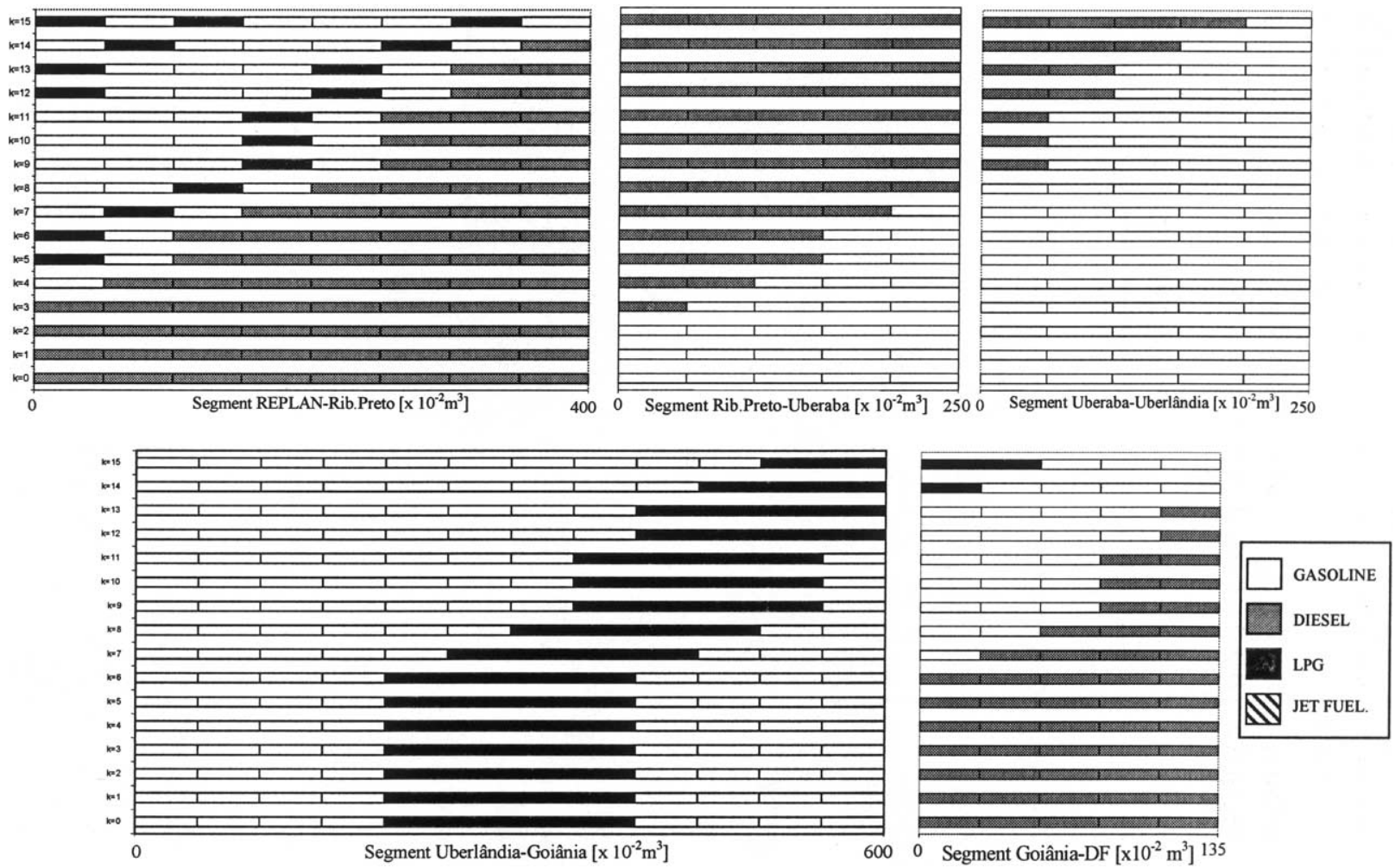

Fig. 10. Pipeline transportation profile for example 2 
ments (see Fig. 10). From $k=7$, there is transfer in all segments whenever the refinery feeds the pipeline because products are always unloaded at the fourth and the fifth depots, simultaneously. Note that in this example all $X U_{p, d, k}$ variables are zero that is, a portion of the product at the end of the fourth segment is always sent to the following one.

The results obtained for this instance show that inventory levels at all depots must remain at their lowest level as long as possible. For instance, products with high demand levels such as gasoline in Goiânia and diesel in Brasília are unloaded from the tanks in the beginning of the horizon. The tanks just receive additional amounts close to the end of the scheduling horizon.

\section{Conclusions}

An optimization model for the scheduling of systems for product distribution has been addressed in this paper. The problem is composed of tanks in the refinery, one multiproduct pipeline, and several distribution depots with tanks for derivatives. A major challenge in the problem is to monitor product content in the pipeline that is subject to intermittent operation.

The problem was first formulated with the use of disjunctive programming. Then, an MILP model that relies on discrete-time and divides the pipeline segments into packs of equal size was developed. Key decisions of this model involve loading and unloading operations of tanks and of the pipeline. Several operating constraints were incorporated in the model, including interface constraints, capacity constraints, mass balance constraints and mainly logical constraints that rule pipeline operation.

The proposed model was then solved for a large-scale example that contains pipeline segments of similar size. The model was successfully able in avoiding time periods of high-energy costs and at the same time managed to fulfill all product demands. Although the obtained results were adequate, several drawbacks were detected in order to address real-world scenarios. First, the model allows at most one unloading operation from the entire system at each time interval. Moreover, this approach may generate problems that are computationally intractable depending on the discretization level adopted, in particular for problems with discrepant segment capacities.

Consequently, a second model was proposed that it is based on packs of different sizes, which avoids the explosive growth in size. An interesting feature of this model is that despite the ability of handling larger systems, the number of binary variables is unaffected by such approach. The resulting approach presented good performance for a real world-system that contains five depots and four products. The corresponding large-scale MILP model contains 6316 continuous variables, 420 binary variables and 9393 constraints and was solved for a relaxation gap of less than $6 \%$ for a time horizon of over 3 days.

\section{Acknowledgements}

The authors would like to thank CAPES for financial support. Special thanks to Petrobras Logistics Coordinator Marlise Fany Lehner.

\section{References}

Bodin, L., Golden, B., Assad, A., \& Ball, M. (1983). Routing and scheduling of vehicles and crews: the state of the art. Computers and Operations Research 10 (2), 62.

Bonnelle, P., \& Bos Feldman, M. (1999). Automating the scheduling process. NPRA computer conference, Kansas City.

Brooke, A., Kendrick, D., \& Meeraus, A. A. (2000). GAMS-a user's guide (release 2.50). Redwood City: The Scientific Press.

Das, S. K., \& Sarin, S. C. (1994). An integrated approach to solving the master aggregate scheduling problem. International Journal of Production Economics 34, 164.

Escudero, L. F., Quintana, F. J., \& Salmerón, J. (1999). CORO, a modeling and an algorithmic framework for oil supply, transformation and distribution optimization under uncertainty. European Journal of Operational Research 114, 638.

Ilog (1999). Ilog CPLEX (6.5) user's manual. Gentilly (France): Ilog Corp.

Jones, W. M. C., \& Paddock, K. F. (1982). Transport by pipeline. In G. D. Hobson (Ed.), Modern petroleum technology (5th ed. Part I). England: Wiley.

Katzer, J. R., Ramage, M. P., \& Sapre, A. V. (2000). Petroleum refining: poised for profound changes. Chemical Engineering Progress 96 (7), 41.

Lee, H., Pinto, J. M., Grossmann, I. E., \& Park, S. (1996). Mixedinteger linear programming model for refinery short-term scheduling of crude oil unloading with inventory management. Industrial and Engineering Chemistry Research 35, 1630.

Más, R., \& Pinto, J. M. (2002). A mixed-integer optimization strategy for oil supply in distribution complexes. Optical Engineering 4, 23.

Maturana, S., \& Contesse, L. (1998). A mixed-integer programming model of the logistics of sulfuric acid in Chile. International Transactions in Operational Research 5 (5), 405.

Moro, L. F. L., \& Pinto, J. M. (1998). A mixed integer model for short term crude oil scheduling. AIChE 1998 annual meeting, session 241, Miami Beach (FL).

Pinto, J. M., \& Grossmann, I. E. (1998). Assignment and sequencing models for the scheduling of process systems. Annals of Operations Research 81, 433.

Pinto, J. M., \& Joly, M. (2000). Mixed-integer programming techniques for the scheduling of fuel oil and asphalt production. European symposium on computer aided process engineering - 10, Computer Aided Chemical Engineering, 8, 1063.

Pinto, J. M., Joly, M., \& Moro, L. F. L. (2000). Planning and scheduling models for refinery operations. Computers and Chemical Engineering 24, 2259.

Pirkul, H., \& Jayaraman, V. (1998). A multi-commodity, multi-plant, capacitated facility location problem: formulation and efficient heuristic solution. Computers Operations Research 25 (10), 869. 
Ponce de Leão, M. T., \& Matos, M. A. (1999). Multicriteria distribution network planning using simulated annealing. International Transactions in Operational Research 6, 377.

Raman, R., \& Grossmann, I. E. (1994). Modeling and computational techniques for logic-based integer programming. Computers and Chemical Engineering 18 (7), 563.

Sasikumar, M., Prakash, P. R., Patil, S. M., \& Ramani, S. (1997). Pipes: a heuristic search model for pipeline schedule generation. Knowl-Based System 10, 169.

Shah, N. (1996). Mathematical programming techniques for crude oil scheduling. Computers and Chemical Engineering 20 (Suppl.), 1227.

Shobrys, D. E., \& White, C. D. (2000). Planning, scheduling and control systems: why can they not work together. Computers and Chemical Engineering 24, 163.

Tahmassebi, T. (1998). An approach to management of multilevel distribution systems for consumer goods and chemicals industry under information uncertainty. Computers and Chemical Engineering 22 (Suppl.), S263.

Techo, R., \& Holbrook, D. L. (1974). Computer scheduling the world's biggest product pipeline. Pipeline Gas Journal 4, 27.
Vakharia, A. J., Erengüç, S. S., \& Simpson, N. C. (1999). Integrated production/distribution planning in supply chains: an invited review. European Journal of Operational Research 115, 219.

Van der Bruggen, L., Gruson, R., \& Salomon, M. (1995). Reconsidering the distribution of gasoline products for a large oil company. European Journal of Operational Research 81, 460.

Vecchietti, A. R., \& Grossmann, I. E. (2000). Modeling issues and implementation of language for disjunctive programming. Computers and Chemical Engineering 24, 2143.

Wilkinson, S. J., Cortier, A., Shah, N., \& Pantelides, C. C. (1996). Integrated production and distribution scheduling on a Europewide basis. Computers and Chemical Engineering 20 (Suppl. B), S1275.

Wilkinson, S. J., Shah, N., \& Pantelides, C. C. (1994). Scheduling of multisite flexible production systems. AIChE 1994 annual meeting, session 235, San Francisco (CA).

Zhao-ying, C. (1986). Decision support system for management of oil pipeline. In L. F. Pau (Ed.), Artificial intelligence in economics and management. Amsterdam: Oxford. 